\title{
Upgrading the Glycerol from Biodiesel Production as a Source of Energy Carriers and Chemicals- A Technological Review for Three Chemical Pathways
}

\author{
Abel Rodrigues ${ }^{1,2}$, João Carlos Bordado ${ }^{3}$ and Rui Galhano dos Santos ${ }^{3, *}$ \\ 1 INIAV, Ministry of Agriculture, 2780-159 Oeiras, Portugal; abel.rodrigues@iniav.pt \\ 2 MARETEC - Research Center, Instituto Superior Técnico, Av. Rovisco Pais, 1049-001 Lisboa, Portugal \\ 3 CERENA-Centre for Natural Resources and the Environment, Instituto Superior Técnico, Av. Rovisco Pais, \\ 1049-001 Lisboa, Portugal; jcbordado@tecnico.ulisboa.pt \\ * Correspondence: rui.galhano@tecnico.ulisboa.pt or rui.galhano@ist.utl.pt; Tel.: +351-21-841-9127
}

Received: 29 September 2017; Accepted: 7 November 2017; Published: 9 November 2017

\begin{abstract}
Glycerol is a by-product of biodiesel obtained from biomass, accounting for $10 \%$ of the biodiesel production. In the context of a green economy, aiming for a reduction of the emission of atmospheric greenhouse gases emissions, the demand of biodiesel is expected to increase vastly, in parallel with a side glut supply of glycerol. Given the high cost of biodiesel compared with its fossil congener, upgrading of glycerol into added-value products can represent a secondary income source and turn the production of such alternative fuels economically sustainable in the long term. The glycerol obtained as by-product of biodiesel from biomass is in a crude form and must be purified. Some industrial solutions and applications were therein geared. The survey presented in this work, based on a reviewing of the existing literature, examines three routes for the valuing glycerol into energy carriers and chemicals, namely, carbonation, acylation, and steam reforming to hydrogen. The latter is embodied of great interest and importance, insofar that hydrogen by itself is considered as straighforward clean fuel for transportation uses, due to its high calorific power and to recent advances in fuel cells. We also have focused on the chain value from biomass to energies carriers through these pathways.
\end{abstract}

Keywords: glycerol; purification; upgrading; carbonates; acetins; steam reforming; energy carriers; review; biomass

\section{Introduction}

About $80 \%$ of global energy production derives from carbonaceous fuels, which include petroleum, coal, and biomasses. From these sets of feedstocks, liquid biofuels are energy carriers including bioethanol, biomethanol, biodiesel or bio-oils that can be produced from plant biomasses. Bio-oils can be regarded as liquid fuels obtained from biomasses, like agricultural and forestry by-products by thermochemical or biochemical processes [1]. Bioethanol is derived from feedstocks such as wood, straw or corn. Biodiesel is also another relevant renewable fuel which can be obtained by transesterification of glycerides with methanol, consisting thereby of fatty acid methyl esters (FAME). Glycerides can be found in oleaginous products, such as cooking oil, rapeseed oil, waste greases, pork lard, biomass from algae, i.e., in almost any vegetable oil or animal fat. Oleaginous crops are the dominant feedstock used in the production of biodiesel [2]. Latest advances in the understanding of the biochemistry of seed oil biogenesis and the cloning of genes which are involved in fatty acid and oil metabolic pathways, have allowed one to obtain oilseed crops that produces tailored oils for particular applications and also their subsequent use for novel oleaginous crops. For example, it was substantiated that vegetable oils with high omega-7 monounsaturated fatty acid (MUFAs) content, have considerably 
improved qualities for biodiesel. The fuels obtained from such tailored crops offer better oxidative stability, nitrogen oxides (NOx) emissions and ignition quality [3]. Rapeseed (Brassica napus) is the most used raw material in Europe for biodiesel production, accounting for $55 \%$ of the total production. Soybean (Glycine max), is the dominant biodiesel feedstock in the US and South American countries such as Brazil and Argentina. Biodiesel has been manufactured at an industrial scale in European Union from 1992 and currently there about 250 plants with a production capacity of some 23 million tons [2]. As recently as 2005, EU accounted for nearly $89 \%$ of global biodiesel production. Algae, included in the so-called third-generation biofuels group, can grow in every place reachable by solar radiation and are a biologically relevant source of biological oil, insofar that the yield oil per area unit is about 200 times higher than the yield from the best performing plant/vegetable oils. Microalgae are the fastest growing photosynthesizing organisms, completing an entire growing cycle in a matter of days. Such organisms achieves a yield of 46 tons of oil/hectare/year, of an order of magnitude of as much as $50 \%$ of weight yield [4].

Vegetable oils can be regarded as the compounds deriving from plants that are more chemically similar to fossil oils. Those oils are the energy supply needed for plants to germinate. The use of vegetable oil, as an alternative to fossil fuel, to produce biodiesel is highly efficient, in terms of energy conversion, with a yield of about $80 \%$. Over the entire life cycle, this yield is lower, e.g., if the energy inputs for cultivation process of plants in the field is considered. In 2008 the yearly world production of vegetable oil from agriculture was of about 125 million tons, roughly corresponding to $3 \%$ of the fossil oil consumption. Of that production, about $85 \%$ was aimed for food. The available projections are that by 2030 vegetable oil could globally replace $3 \%$ of the fossil oil and $6 \%$ of the vehicle fuel [5].

In this context, the production of biodiesel can be based on the cultivation of non-edible, drought tolerant oil plants on non-used land. Indeed, the large increasing demand of feedstocks for biodiesel production tends to lower the supply of food from agriculture, increasing the odds of non-edible sources (second generation biofuels) such as waste cooking oil, grease, jatropha seed oil, and algae, avoiding thereby the edible feedstocks (second generation biofuels). The quality of materials used in biodiesel production must, however, be checked for impurities in order to improve the final product. Jatropha curcas is a perennial tropical bush which can reach an annual oil yield of 5-8 tons.ha ${ }^{-1}$, of the same order of magnitude as palm oil, with a life expectancy up to 50 years. This bush can grow under different soil and climatic conditions: arid, semiarid and wastelands, with a variety of annual rainfall ranging between $250 \mathrm{~mm}$ and $1200 \mathrm{~mm}$, and survive for periods of two years without rainfall. In Calabria, Italy, Jatropha is gaining increasing importance as a potential biodiesel feedstock [5-8]. China is a country where biodiesel production from jatropha feedstock is expected to grow from $5 \mathrm{Mt}$ now to $12 \mathrm{Mt}$ by 2030, with a total potential cultivation area of $8.5 \mathrm{Mha}[9,10]$. This plant could contribute to the substitution of $12 \%$ of global fuel consumption by vegetable oil, simultaneously with an improvement of climatic and economic prospects of drought-prone tropical and Mediterranean lands [5]. Nevertheless, some controversy arises about the feasibility of this species, in in habitats with low productivity, insofar that the lack of moisture and nutrition are, of course, invariably reflected in its seed production [11]. Crop yield and harvesting are relevant time consuming processes in the whole production cycle. For example, it can take 4 for 7 years for the harvesting of first yield of oil crops such as jatropha (4-5 years) or pongamia (6-7 years) [12].

Biodiesel is a promising renewable fuel that significantly reduces $\mathrm{CO}_{2}$ emissions, comparatively with fossil fuels. The global production of biodiesel, as mentioned above, has been rising. In the period 2000-2012 the daily production increased from 15 to 430 thousand barrels [13]. The estimated global production of biodiesel in 2015 was 31,000 ML and the estimates for 2020 point a production of 110,000 ML. Biodiesel cost is higher by about 0.89 per volume unit, when compared with fossil diesel. The high production cost, primarily driven by high energetic consumption, is the main factor accountable for such values [14]. In many countries, a blending of fossil diesel with a small percentage of higher costly biodiesel is however prescribed. The life cycle from the plant to biodiesel production is comprised by an intricate cycle of multiple steps: crop production, harvesting, seed cleaning and 
drying, oil and meal production and later transesterification using extracted oil [15]. Investment for a biodiesel production unit requires $78 \%$ feedstock price costs and $93 \%$ of returns are expected from biodiesel yield. Until 1999, the main glycerol supplier was the oleo-chemicals industry. Ten years after, the biodiesel industry became the main global supplier. The increased supply of the feedstock, a priority was given to the finding and development of new chemical products as technological chemical engineering platforms. Between 2000 and 2007, the global number of research papers focusing on glycerol technologies doubled to more than 7000. In the same period a huge development of new catalytic pathways to high valued products from glycerol, also occurred [16].

Essentially, the industrial production of biodiesel consists in a triglyceride transesterification involving three molecules of methanol and a basic or acid catalyst, under a one or two-phase reaction systems, in operative conditions of high pressures and temperatures, to obtain biodiesel while glycerol arises as a byproduct. The transesterification reaction for biodiesel production, consists therein in replacing the glycerol molecule by an alcohol with fewer carbon atoms, for example with one methanol molecule, forming a monoglyceride, or with ethanol forming a diglyceride $[14,17]$. These glycerides have much better fuel properties than the original oil. This transesterification reaction is an equilibrium reaction, occurring in several steps, with the aid of catalysts which, in the end, can be incorporated in the structure of reaction products. The final product will be a blend integrating a fraction of the original non-purified triglycerides, intermediary products, unreacted alcohols, glycerol, a catalyzer and even foams occurring through saponification in an aqueous solution. Chemically, biodiesel consists of mainly alkyl (especially methyl) esters, whilst fossil diesel consists of alkanes and aromatic hydrocarbons $[1,17]$. Heterogeneous catalyzers available form an insoluble phase and thereby can be reused without contamination of final product [17]. The biodiesel production is also linked to the theoretical concept of the biorefinery plant. This concept envisages a broader integrated use of biomasses, aiming to achieve economic and environmental sustainability. The first generation biorefinery $(1 \mathrm{G})$ for biodiesel has a first stage of oil separation by chemical or mechanical extraction and a further stage of extracting the crude vegetable oil [2].

Glycerol (propane-1,2,3-triol) is a multi-functional organic compound, showing hydrophilic and hydrophobic properties due to a stable chemical structure with three hydroxyl groups. Due to its thermal stability, a high energetic availability for bond breaking and formation of other compounds is required. The glycerol obtained as byproduct from biodiesel production, with a mass yield of $10 \%$, is the so-called crude glycerol containing free fatty acids (FFA) [18], methanol or fatty methyl esters from the transesterification reaction. Despite the low price of glycerol, its purification is an expensive process, especially for small and average companies; therefore, researchers have sought different possibilities to incorporate crude glycerol, optionally with a very simple purification step, into various branches of industry.

Under the low prices of crude glycerol, a potential of crude glycerol for biorefineries exists, which deliver high value-added products. There are more than 1500 end products of glycerol and thereby the supply market and price forecasts are complex processes [19]. The glut of unrefined glycerol can turn new applications of this feedstock contributive for compensate the difference in costs of biodiesel, relatively to fossil diesel, and also contributing to reduce the energetic requirements for biodiesel production. The global production of crude glycerol was of about 4 Mtons in 2012 with a projection of 4200 ML by 2020 [14]. This increased production was of course reflected on a drastic falling of the stuff prices with the prices of refined glycerol declining from about $3200 \$ /$ ton in EU and $2000 \$ /$ ton in the US in 1995 to under $500 \$ /$ ton and $600 \$ /$ ton in 2010 [13]. The prices of crude glycerol were lower by about a threefold factor. In 2013, its price recovered to about $900-965 \$ /$ ton, with the corresponding price of crude glycerol lower on a fourfold scale [14]. These low prices of glycerol are of course beneficial for improving the potential of possible applications, and are very dependent on the biomass used in the production of the biodiesel. The world glycerol market will be worth of about 2.52 USD in 2020 with biodiesel as the main source of the feedstock [20]. Crude glycerol can be purified, e.g., by distillation, to value added products, used for example in cosmetic and pharmaceutical 
industries. As examples of proposed applications for non-refined crude glycerol, figure anaerobic digestion, animal feeds, and thermochemical or biological conversions for value-added products $[2,21]$.

Combustion of crude glycerol is an inconvenient process due to its low heating value, high self-ignition temperature, acrolein formation, high emissions, high emissions and salt content. Even with swirl refractory burners, emissions of particulate and VOC were significantly higher, when compared with other feedstocks. There has been a lot of apprehension about the acrolein formed during this process, because of its high toxicity, however recent study proved that its emissions are not high and with a little effort they can be lowered to acceptable levels [22]. Such a method of utilization, however, does not use the whole potential of crude glycerol, which could be materialized in other applications. The use of crude glycerol on solid briquettes although not unbeneficial for environment, showed a negative impact on physical and mechanical properties on the solid fuel.

Theoretically, glycerol in a combined energy and power unit, could supply the entire energy consumption of a biodiesel plant [23]. Overall, the purification of crude glycerol obtained from biodiesel is a necessary process insofar that the major chemical conversions require a purified version of this feedstock.

In a nutshell, this work aimed to evaluate the actual technological status of processes for purifying crude glycerol, through carboxylation, acetylating and reforming pathways. The main industrial techniques for converting crude glycerol for high purity glycerol were also considered. The main products obtained through these pathways are glycerol carbonate, glycerol acetates, and hydrogen, respectively. These are chemical products with an enormous industrial potential for chemical conversion and energy carrying (Figure 1). Our three-prong approaches were settled on the potential of these pathways for integrating clusters from biomass production, under the actual context of a crucial needing of mitigation of atmospheric carbon emissions, through a carbon light economy from which biomass is a fundamental buttress.

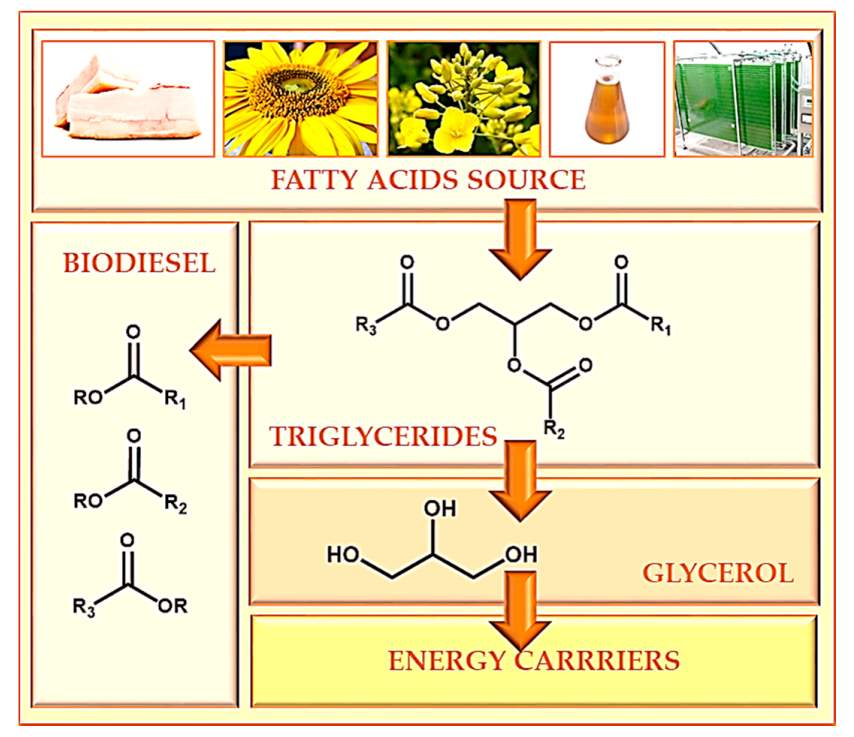

Figure 1. Production of energy carriers from biodiesel and glycerol.

\section{Techniques of Glycerol Purification}

Two phases are formed during biodiesel production, due to distinct densities and polarities: the upper phase is the biodiesel while the crude glycerol is found in the lower phase. Crude glycerol is a mixture of components such as glycerol, water, methanol, soap, and non-glycerol organic matter (NGOM).

The components of crude glycerol vary, e.g., with the biomass feedstock or with the technical variables of biodiesel production. If the feedstock stuffs for biodiesel are seed oils such as rapeseed, 
soybean or waste cooking oils, a crude glycerol containing amounts in the range $62.5-76.6 \%(\mathrm{w} / \mathrm{w})$ glycerol is obtained. Homogeneous base catalysts used for biodiesel production results in higher salt contents $(5-7 \% \mathrm{w} / \mathrm{w})$ in crude glycerol, comparatively with heterogeneous base catalysts. Enzymatic catalyzed transesterification is nowadays optimized to bypass the drawbacks associated with acid and base catalyzed esterification [18]. Among these inconveniences figure the higher energy requirements, the environmental pollution and the difficulties to the recovery of the catalyst and glycerol. Therein, enzyme catalysts produce a high purity glycerol, allowing easier recovery of product and catalyst reuse and mild reaction condition requirements, but there are also the handicaps of enzyme catalyst implementation at industrial scale, which are the high cost of enzymes, enzyme deactivation and slow reaction rates.

Anyway, the variable amounts of glycerol $(\mathrm{w} / \mathrm{w})$ in crude glycerol obtained from biodiesel, ranging between $20 \%$ with jatropha oil [24] and $90 \%$ in sunflower oil with basic catalysis [25] makes the assessment of crude glycerol refining unavoidable. This happens, notwithstanding the circumstance that crude glycerols can be directly used for some forms of conversion. The purification process must of course be adapted to take in consideration the crude glycerol composition, its use and a benefit/cost control of the whole process should thereby carried out [26]. The purification of crude glycerol, for high value applications such as the pharmaceutical or cosmetic industries, requires expensive processing equipment. To this end, glycerol can be refined up to $95.5 \%$ and $99 \%$ purities in large scale biodiesel factories. The crude glycerol process is however prohibitive for small-scale producers who must develop other feasible uses for this feedstock.

The typical refining process of crude glycerol includes three steps. Those steps are: neutralization to remove the soaps and salts, a vacuum evaporation to eliminate methanol and water and a further refining for improve glycerol purity. In the neutralization stage a strong acid (e.g., phosphoric acid, hydrochloric acid or sulfuric acid) is added to convert soaps into free fatty acids. This neutralization step results usually in the separation of crude glycerol into a three-layer mixture, wherein the insoluble free fatty acids are allocated to a top stratum and easily separated, the glycerol, water and alcohol (e.g., ethanol or methanol) are located in an intermediate stratum and the inorganic salts are in the bottom stratum. Several variants were proposed for the neutralization step. For example, Kongjao et al. [27] showed that a high purity glycerol $(93.34 \% \mathrm{w} / \mathrm{w})$ could be obtained from waste oil methyl ester, with $\mathrm{H}_{2} \mathrm{SO}_{4}$ at $\mathrm{pH} 1$, after sequent neutralizations with $12.5 \mathrm{M} \mathrm{NaOH}$ and mechanical treatments.

Hajek et al. [28], proposed glycerol acidification, following vegetable oil conversion to biodiesel, with a strong acid addition for transforming impurities, such as soaps, into high valued fatty acids. Javani et al. [29], in the same way, proposed that crude glycerol should produce potassium phosphate as a by-product from a sequence of reactions of saponification and acidification. These authors suggested these proceedings under a wider strategy for producing purified fatty acids and glycerol, with a lower biodiesel production.

The second stage for purification is the extraction of methanol. Indeed, in transesterification reactions, excess methanol is usually applied for shifting the reactions equilibrium towards higher yields of biodiesel. Excessive un-reacted methanol is considered as a hindrance due to its toxicity in main chemical applications. This alcohol is allocated on the methyl ester and crude glycerol phases [30]. Due to its low boiling point the predominant method for removing methanol is vacuum distillation. At an industrial scale, falling film evaporators are prescribed due to a shorter contact time at evaporating temperatures, given the glycerol susceptibility to higher temperatures which can result on glycerol decomposition. The mass yield of glycerol after the distillation stage is of about $85 \%$.

The attainment of a high purity glycerol, of say of $95 \% \mathrm{w} / \mathrm{w}$, or higher, requires a third stage of purification, through four deep refining technologies which are vacuum distillation, ion exchange, activated carbon absorption and membrane separation. The distillation of chemical compounds which are susceptible to high temperatures, such as glycerol, is facilitated by carrying out the operation on a column under vacuum [31]. The use of this technology, by reducing the operation 
temperatures, avoids the polymerization of glycerol into polyglycerol at temperatures higher than $200{ }^{\circ} \mathrm{C}$, or the dehydration under slightly acidic conditions at temperatures higher than $160{ }^{\circ} \mathrm{C}$, among other inconvenient side-reactions, so the distillation has to be carried out under vacuum wherein operative temperature, pressure and $\mathrm{pH}$ conditions are controlled to prevent glycerol degradation. Vacuum distillation is indeed the main technology for industrial refinement of glycerol with noticeable advantages such as a possible feasibility for small to large scale continuous operation, and process flexibility adapted to distinct raw and final feedstocks. The drawback of distillation, the main thermal important thermal separation technology, is its high energy consumption, corresponding to about $50 \%$ of plant operation costs. This hindrance has led to several improvements, culminating with somewhat interesting options such as cyclic distillation and dividing wall distillation column.

Cyclic distillation columns involves operating one distillation column in a cycling method-alternating between the liquid and vapor flow, with lower energetic consumption, much better partition easiness and allowing an adaptation of old towers by changing their internal structures [32,33]. Under cyclic distillation two steps occur: a vapor-flow step when the impulsion of the rising vapor precludes liquid downflow and liquid remains stationary on each plate, followed by a liquid flow period when vapor flow is ceased, reflux and feed liquid is supplied, and liquid flows down the column, along the several trays. The mathematical modeling of this distillation is based on steps concerning mass flow of the volatile component on the contact stage, during the vapor supply period, the liquid flow hydrodynamics during the liquid period or the liquid overflow from tray to tray, the mass transfer kinetics, determined by local point efficiency, mainly the Murphree efficiency, and an equilibrium line of vapor composition as a function of liquid composition. The whole system of equations can be solved analytically e.g., with the Matlab software package. Two chemical engineering case studies concerning cyclic distillation shown by Maleta et al. [32], displayed the clear advantages of this technology over the more traditional form, namely: lower capital expenditure, reduced energetic consumption and savings in operating costs, higher separation and quality of products and higher productivity comparatively to traditional distillation.

Dividing wall column technology (DWC), which is used for ternary separations, was proposed for a simple step methanol recover and glycerol separation [34]. The DWCs systems are exploited for the separation of a broad range of chemicals such as hydrocarbons, alcohols, aldehydes, or ketones. These systems are released as packed columns constructed by Julius Montz GmbH (Hilden, Germany), and its technical specifications are mostly classified. In 2010, there were an estimated 100 dividing wall columns operating in the world and by now the corresponding figure must be of a hundredfold magnitude.

Basically the DWC is an implementation of the Petlyuk configuration [35], originally patented in 1949, consisting in a distillation column, with a vertical partition dividing it in two sides: a pre-fractionator and a main fractionate. The feed stream is introduced into the pre-fractionator, the feed side of the column, whilst a side stream is removed from the main column. The lightest component goes to the top of the device as distillate, the side stream contains the intermediate boiling point component and the heaviest components go downwards to the bottom. For industrial applications the DWC technology is characterized by significant benefits over the conventional applications with reductions of around 30\% in investment costs and $40 \%$ in energy savings. This technology can be generalized to mixtures with more than three components as to reactive, azeotropic or extractive distillations [36]. For promoting the reliable design methodologies for generalizations of DWC in industrial applications, or for maintaining the compromise between complexity and correctness, the mathematical calculations options available include differential equations systems, concerning total mass at plate $j$, mass balance for component $i$ at plate $j$ and dynamic calculation of temperature at plate $j$, resoluble by numerical methods [37].

The DWC technology study of Kiss and Ignat [34], for methanol and glycerol separations from biodiesel, follows steady state and dynamic simulations, through a sequential dynamic quadratic programming method, implemented in digital packages, which is considered as a good methodology 
for addressing nonlinearly constrained optimization problems. This study focused on the separation of the ternary mixture for the direct distillation classic sequence and the DWC technology, with a base feed of $2.9 \mathrm{kgh}^{-1}$ equivalent to $100 \mathrm{ktpy}$, considering as objective the attainment of $99.5 \mathrm{wt} \%$ for each product. The considered mass concentrations for reactants and products of the reaction of transesterification, are under the ratio 100:22:11 for biodiesel, methanol and glycerol. The amount of methanol used as reactant can surpass the stoichiometric ratio by as much as $50 \%$, leading to a need of recovery and recycling of that compound.

The composition of the feed mixture is also dependent on the biodiesel production process, e.g., acid or basic catalyzed, of the amount of water used in the biodiesel washing and of the water derived from the FFA pretreatment step. Usually, the amounts of water are lower than these of methanol and glycerol. The steady state simulations were performed for equations of mass balance, equilibrium relationships, summation equations, and enthalpy balance, with the AspenTech Aspen Plus package. The direct distillation sequence and DWC alternative configurations were upgraded on minimal energy requirements, through sensitivity analysis and sequential quadratic programming tools from Aspen Plus. The optimization variables used on calculations were the total number of stages, feed stage location, side stream location, length of dividing wall, reflux ratio and liquid and vapor split. DWC technology allowed controlling both operative capital and operative costs as dynamics of compounds separation processes. Indeed, two multi loops are stabilizers of the column and other three specify the product purities in set points. In this study, DWC allowed one to reduce carbon dioxide emissions by $25 \%$, energetic consumption by $27 \%$ and equipment expenses by $12 \%$. Dividing wall column technology allows refurbishing existing plants for biodiesel production or to set up new plants as well.

Ion exchange purification techniques allow obtaining higher quality of refined glycerol, by removing undesirable components such as fatty acids, inorganic salts and free ions, at room temperature with lower energy inputs. The first commercial unit to use this technology for crude glycerol purification started operating as early as 1951 with a conversion of 11.9 tons/day. The input material which was crude glycerol from soap lye, contains usually $82 \%$ of glycerol, $10 \%$ of ash, moisture and other impurities. A 95-99\% of glycerol content of superior quality was obtained, with a low investment unit, making this modality adequate for smaller plants. This technology was later upgraded for crude glycerol from biodiesel, with the introduction of gel type acidic ion exchange beads for eliminating fatty acid salts, inorganics salts and free ion impurities [38,39]. Isahak et al., demonstrated, at lab scale, the performance of the Amberlite IRN-78 and Amberlite 200 resin types for the refinement of crude glycerol, with results indicating that the ion-exchange resin method is apt to remove undesired components such as free ions and inorganic salts. Still, problems linked to poor bed regeneration, column fouling by fatty acids, soaps and oils and large quantities of waste water, should be addressed for a throughout feasibility of ion exchange methods application to crude glycerol purification. Frequent cleaning is required for avoiding fouling of equipment by fatty acids.

The adsorption with activated carbon is a common purification method for reducing color and adsorbing same small molecular components, such as lauric and myristic acids among others [40]. Manosak et al. [40] reported a color reduction of $99.7 \%$ and a purification of $84.1 \mathrm{wt} \%$ with an amount of activated carbon of $200 \mathrm{~g} / \mathrm{L}$ of crude glycerol. The refined glycerol still complied with the requisites of the norm BS 2621:1979. Other authors [41] found a significant glycerol purification with a sewage sludge derived carbon activated with $\mathrm{KOH}, \mathrm{K}_{2} \mathrm{CO}_{3}$ and $\mathrm{H}_{3} \mathrm{PO}_{4}$, named $\mathrm{KOH}-800 \mathrm{AC}$, from a set of 15 equivalent kinds of prepared formulations. The latter purification was of about 1.06 higher than the achieved with commercial activated carbon.

Another approach for purification of crude glycerol is based on alternative combination of chemical and physical processes. Essentially, under chemical treatment, the crude glycerol fraction can react with acid for converting the alkoxide salts to the corresponding alcohol and with the fatty acid carboxylate salts to the corresponding free fatty acid. The latter can be removed by extraction or decantation. For example, a high purity glycerol (93.34\%) with low ash levels $0.00045 \%(\mathrm{w} / \mathrm{w})$ 
and $5.16 \%(\mathrm{w} / \mathrm{w})$ of NGOM was obtained at lab scale using repeated cycles of acidification to the a $\mathrm{pH}$ in the range 1-6, using $1.19 \mathrm{M} \mathrm{H}_{2} \mathrm{SO}_{4}$, allowing phase separation and removal of the glycerol-rich middle phase, followed by neutralization of the removed glycerol phase with $12.5 \mathrm{M} \mathrm{NaOH}$ [18].

An emerging technology with high potential crude glycerol purification are membrane separation (MS) processes, which are environmentally-friendly, simple to operate, with low energy and cost consumption, and capable of purification corresponding to glycerol contents of up to $99.0 \%(\mathrm{w} / \mathrm{w})$ [42]. MS technology is applied through modalities of, e.g., ultrafiltration, microfiltration, nanofiltration or reverse osmosis. The avoidance of water for washing, which is needed for example in purification by ion exchange technology, is another environmental friendly advantage of this technology. A technological modality for purification of glycerol, through membrane separation, was developed through the patented high efficiency electro-pressure membrane technology, developed by EET Corporation following a synergic approach, wherein the membrane units work under integration with nanofiltration and/or reverse osmosis processes in a single unit operation. Jeromin et al. [43], proposed the removal of unreacted oil or fat in glycerol rich solutions through the application of pressure in ultrafiltration membranes.

As a contribution to the knowledge of the fouling process in membrane separation, Indok et al. [44], tested the efficiency of two ultrafiltration (UF) polymeric membranes to clarify synthetic glycerin-rich solutions containing triglycerides (TGs), employing a commercial TG (RBD Palm Olein). The membranes were tailored using poly (ether sulfone) (PES) and poly(vinylidene fluoride) (PVDF) with a molecular-weight cutoff (MWCO) values of 25,000 and 30,000 Da, respectively. In glycerol-water mixtures containing TG, the contribution of the solute to fouling was more severe, with lower permeation rates, than that of fatty acid (FA). Moreover, the study showed that PVDF membranes provided higher fluxes and lower TG rejection rates (81\%) than PES membranes (91\%). The fouling potential is also influenced by the $\mathrm{pH}$ of solution. The MS is thereby a potential feasible technology for contributing to the sustainability of biodiesel production, but problems linked to fouling, durability and availability of membranes adapted for specific operations still remain and research should be focused on overcoming these drawbacks.

The use of hybrid membranes is an innovation reflected on improving of the membrane performance, through the combination of organic and inorganic materials on the membrane structure. Indeed, the inorganic component was shown to improve the mechanical and thermal properties whilst the organic component preserved the membrane flexibility. For example, composite membranes of poly(methyl methacrylate) ( $\mathrm{PMMA}$ )- $\mathrm{SiO}_{2}$, wherein silica was added to membrane formulation as tetraethoxysilane, were shown to have higher water permeability. Thereby, the hybrid membranes would combine an improvement in water soluble permeation, optimizing the purification of crude glycerol, with better thermal and mechanical properties, resulting on a much higher efficient and sustainable operation.

Another option for purification of crude glycerol is the membrane distillation (MD) [45]. These membrane distillation processes show lower energy costs comparatively to other processes such as distillation, much lower membrane fouling than other membrane processes such as ultrafiltration or lower pressure requirements than pressure driven membrane processes. A wide scope of membranes encompassing polymeric and inorganic membranes of hydrophobic nature can be used in membrane distillation processes. Polytetrafluoroethylene (PTFE), polypropylene (PP) and polyvinylidene fluoride (PVDF) are the most common polymeric membranes used for MD, due to their low surface tension values, and the possibility to tailor their intrinsic properties such as operating temperature and thermal conductivity.

Specifically, PTFE membranes are highly hydrophobic with great thermal stability and chemical resistance, being almost insoluble in a large set of common solvents. Fundamentally, MD is somewhat similar to traditional distillation insofar that both technologies are based on the water vapor equilibrium for separation, requiring the supply of latent heat for phase change. The driving force of MD is a vapor pressure gradient generated by a temperature difference across the membrane. This driving force 
is a pure thermal one and thereby membrane distillation can be carried out at a lower temperature than usual thermal distillation. The penetration of aqueous solution through the membrane pores is prevented by the hydrophobic structure of the membranes [45]. The hydrophobic character of membrane determines that, under MD, only water vapor transport occurs, and originating the so-called concentration polarization process which consists on a higher concentration of solutes at the liquid gas interface than at the bulk mass transfer. The existence of concentration polarization layers at both sides of the membrane is the drawback of MD, reflected on a diminishing of driving force for water vapor transport with a reduction of the transmembrane flux, comparatively e.g., with reverse osmosis. A solution of combination of MD with other membrane separation technologies (e.g., microfiltration or ultrafiltration) has been proposed for increasing the transmembrane flux [46].

\section{Glycerol Carboxylation to Glycerol Carbonate}

Glycerol carbonate is a high valuable product with a wide scope of potential applications and a market price as high as of US $\$ 8141 /$ ton [47] that can be obtained at low cost and high volume from glycerol. Some of these uses are as an intermediate in the synthesis of polymers such as polyesters, hyper-branched aliphatic polyethers, polycarbonates, polyurethanes, polyamides, surfactants, lubricating oils, cosmetics or electrolytic carriers in lithium-ion batteries $[14,48]$. Glycerol carbonate can also be a green alternative to a set of equivalent fossil derivative compounds such as ethylene or propylene carbonate. Glycerol carbonate can be obtained industrially through transesterification with dimethyl carbonate, as an acyl acceptor (Figure 2), with a heterogeneous catalyst producing methanol as by-product, therein allowing for a straightforward separation and purification of glycerol carbonate, beginning with the separation of catalyst by filtration and followed by solvents evaporation with almost 100\% yield. Excess dimethyl carbonate is employed to drive the reaction equilibrium towards the production of the desired product. The procedure of separation by evaporation of compounds is due to the huge boiling point difference between the excess dimethyl carbonate and methanol, compared with glycerol carbonate. Although the glycerol carbonate synthesis through transesterification can be performed without adding a catalyst $[14,18,48]$ its use is, of course, very benefical. As examples of homogeneous catalysts that can be used in the reaction, figure carbonates of potassium and calcium or hydroxides of potassium and calcium. Those catalysts can work at conversion ratios and yields higher than $95 \%$ with reduced reaction time, with dimethyl carbonate/glycerol and catalyst/glycerol molar ratios of 5 and 0.1 , respectively [48].

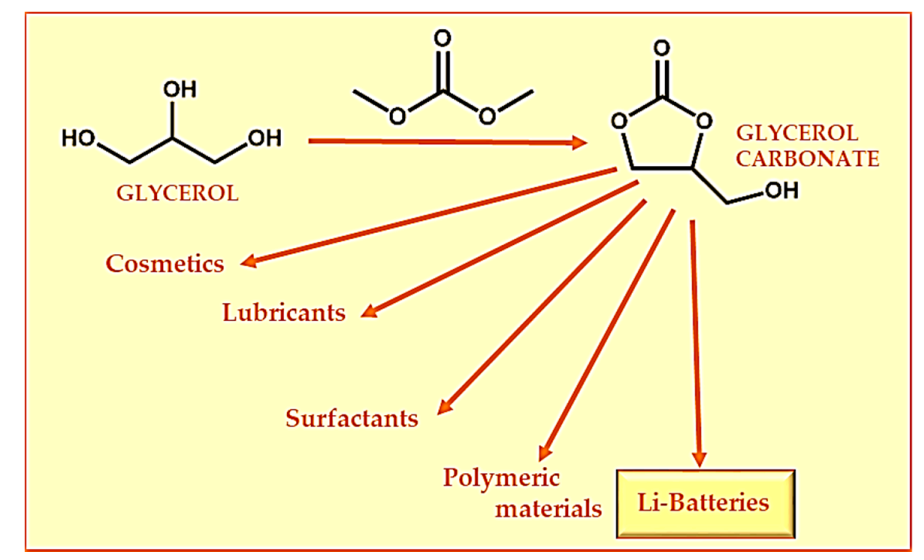

Figure 2. Industrial production of glycerol carbonates and some applications.

However, alkali-hydroxide catalysts pose same problems due to the difficulty in the separation of the catalyst from the final reaction mixture. In the case of biodiesel, water can be used to extract the dissolved catalyst because oil and water are immiscible. In the case of glycerol carbonate synthesis, water cannot be used because both components are miscible, turning removal of catalysts into a high 
energy consuming process which should thereby be avoided. A potential alternative is the use of harmless organic ionic liquids (IL) in the transesterification with dimethyl carbonate to give glycerol carbonate. One IL with great potential is 1-N-butyl-3-methylimidazolium-2-carboxylate. Experimental evidence available for this IL points to high yields of $100 \%$ and $93 \%$ for refined and crude glycerol conversion to glycerol carbonate, respectively, but with longer reaction times and so information about the stability and reusability of the catalyst $[14,18,48,49]$. Heterogeneous catalysts show similar reactivity potential in adapting the transesterification reaction for producing high yields of products, with analogous reaction conditions. As examples of favorable heterogeneous catalysts we have alkaline oxides and mixed oxides of calcium and magnesium, (e.g., $\mathrm{Mg} / \mathrm{CaO}, \mathrm{NaOH} / \gamma \mathrm{Al}_{2} \mathrm{O}_{3}, \mathrm{CaO}$ and $\mathrm{Na}_{2} \mathrm{O}$ ), hydrotalcites or zeolites. Lower reaction rates for the synthesis of glycerol carbonate with obtained with strong base macro-porous ion exchange resins such as Amberlyst $\mathrm{A} 620 \mathrm{H}$ and Amberjet $4400 \mathrm{OH}$ as heterogeneous catalysts. This should be due to the fact that basic catalytic sites are inside the resin beads and that resin surface is hydrophobic [48]. In these conditions, the mass diffusion of hydrophilic glycerol molecules to catalytic sites within the resin is restricted.

However, as a general principle, regardless of the catalyst phase, an established conclusion is that catalytic activity of basic catalysts is very beneficial to the transesterification reaction providing high conversion and yields. On the contrary, acid catalysts, such as sulfuric acid, $p$-toluenesulfonic acid, or acid ion exchange resin heterogeneous porous catalysts (Amberlyst 131Wer and Amberlyst 39W, spherical beads) offer very slow reactivity rates. The catalytic activity increases therein with catalyst base strength [48].

Focusing thereby on basic catalysts, additional considerations about the transesterification reaction for glycerol carbonate production can be made. Firstly, the influence of temperature is determinant for reaction rate either for homogeneous or heterogeneous catalysts. Indeed, the spectrum of results is broad, insofar that glycerol conversion and glycerol carbonate yields can range between $7 \%$ at room temperature and $90 \%$ for heterogeneous catalysts or $100 \%$ for homogeneous catalysts, at temperatures of $75^{\circ} \mathrm{C}$. Experimental evidence from studies with solid heterogeneous base catalysts, such as alkali metal oxide or alkali-mixed metal oxides [4,5], suggested that the base-catalyzed transesterification is not an equilibrium one.

The information available allowed proposing an overall three-step mechanism for the reaction [14,48]. In the first step, the formation of a glyceroxide anion occurs in the presence of a base catalyst. In this step, the weak acid proton reacts with a strong basic catalyst to form the glyceroxide anion and the conjugated acid of the base. Considering the low acidity or electrophilic character of the hydroxyl group, a strong base will be needed for forming the anion. In the second step, the glyceroxide reacts with the carbonyl carbon of a dimethyl carbonate molecule to form a complex intermediate (hydroxyl alkyl carbonate) and a methoxide anion. In the third step, the methoxide anion reacts with the base conjugated acid, formed in the first step, yielding methanol and regenerating the base. In the fourth step, there is a cyclization reaction giving glycerol carbonate plus methanol. A further decomposition of glycerol carbonate in the presence of a high basic catalyst leads to the formation of glycidol, which is a relevant intermediary employed in cosmetic, plastics, pharmaceutical and textile industries [48].

Under lab conditions, the basic homogeneous catalysts leading to conversion and yields of about $100 \%$ are potassium hydroxide, sodium hydroxide, and potassium carbonate. As aforementioned, these catalysts pose some problems, at an industrial level, related with the separation of the dissolved catalyst from the product, making their broad use inconvenient. For heterogeneous catalysts, conversion and yields at $75{ }^{\circ} \mathrm{C}$ range between $20 \%$ and $90 \%$, depending on the catalyst's properties.

The intrinsic catalyst basicity and transesterification rate are highly correlated. In a set of basic heterogeneous catalysts the catalytic activity increases in the following order for uncalcinated catalysts: $\mathrm{CaO}>\mathrm{MgO}>\mathrm{CaCO}_{3}$, in the same order of basic strength of these materials [50].

However, the catalytic activity of $\mathrm{CaO}$ is highly dependent on its purity. Indeed, $\mathrm{CaO}$ can be contaminated with $\mathrm{Ca}(\mathrm{OH})_{2}$, resulting from the reaction of $\mathrm{CaO}$ with air moisture, and $\mathrm{CaCO}_{3}$, 
resulting from the reaction of $\mathrm{CaO}$ or $\mathrm{Ca}(\mathrm{OH})_{2}$ with environmental $\mathrm{CO}_{2}$. Considering that the base strength of $\mathrm{CaO}$ is higher than those of $\mathrm{Ca}(\mathrm{OH})_{2}$ and $\mathrm{CaCO}_{3}$, then the presence of the latter leads to a reduction of the catalytic activity of the $\mathrm{CaO}$. Experimentally it was shown that the conversion and yield of impure $\mathrm{CaO}$ vs. calcinated $\mathrm{CaO}$ are characterized by conversion rates of $74 \%$ and $94 \%$ and yield rates of $64 \%$ and $91.1 \%$, respectively [48]. Calcinated $\mathrm{CaCO}_{3}$ shows a similar behavior, compared to uncalcinated $\mathrm{CaCO}_{3}$. The influence of operative conditions in the glycerol carbonate production for conversion of glycerol, C, and yield, Y, is parameterized by Gómez et al. [48] through the multivariate regression equations:

$$
\begin{aligned}
& \mathrm{C}=-280.9+4.35 \mathrm{~T}+1280.79 \mathrm{CGR}+8.93 \mathrm{MR}-15.65 \mathrm{~T} \times \mathrm{CGR}-0.17 \mathrm{~T} \times \mathrm{MR}+47.16 \mathrm{CGR} \times \mathrm{MR} \\
& \mathrm{Y}=-285.52+4.4 \mathrm{~T}+1477.21 \mathrm{CGR}+4.3 \mathrm{MR}-18.73 \mathrm{~T} \times \mathrm{CGR}-0.13 \mathrm{~T} \times \mathrm{MR}+58.45 \mathrm{CG} \times \mathrm{RMR}
\end{aligned}
$$

where T, CGR and MR are the experimental values for operative temperature, catalyst/glycerol molar ratio and DMC/glycerol molar ratio. A scope of the influence of these three operative variables and their interactions on the overall transesterification reaction for glycerol carbonate can be evaluated from these two equations.

\section{Glycerol Acetylation to Acetins}

Another alternative route for conversion of glycerol produced from biodiesel is the acetylation via esterification (Figure 3) [14,51-53]. The resulting mono-, di- and triacetylesthers have great industrial applications. The triacetylated derivative is known as triacetin (TAG) which can be used in the cosmetic and food industry, as a fuel additive, and as an antimicrobial and emulsifying agent in pharmaceuticals and cigarette filters. The mono- (MAG) and diacetylated (DAG) esters are also known as mono- and diacetin and have uses as cryogenics and as feedstocks for the production of biodegradable polyesters. These glycerol acetyl compounds exhibit physicochemical properties of BD-like fuel and can be utilized in diesel engines as additives for viscosity reduction without modification.

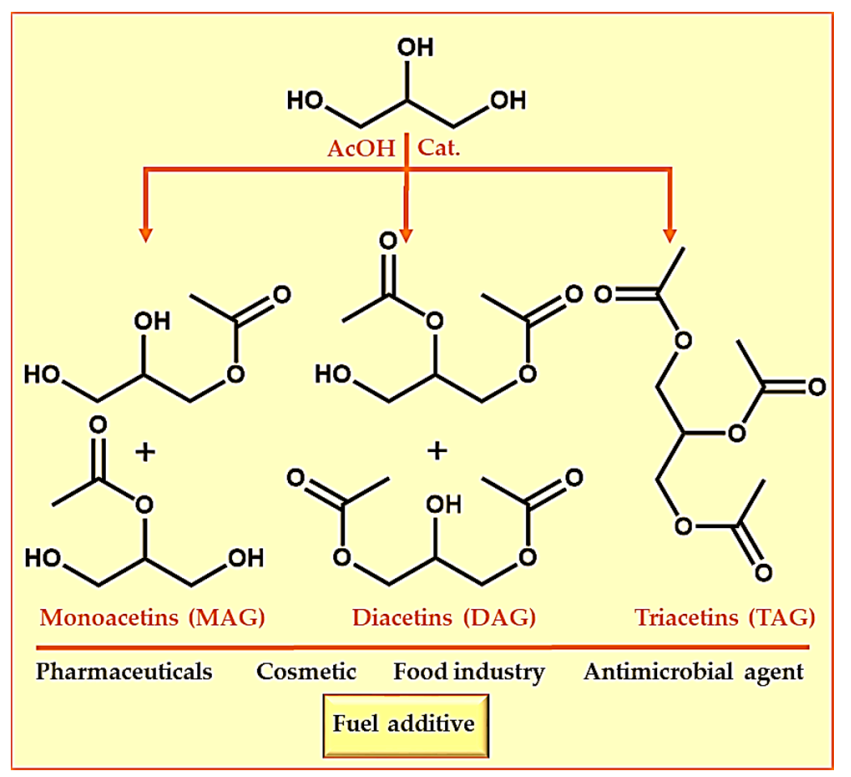

Figure 3. Industrial production of acetins and applications.

Esterification is a reversible chemical reaction, and the addition of one reagent in excess is a way to shift the reaction equilibrium towards the desired products. This reagent should be either the corresponding carboxylic acid, namely acetic acid, with lower cost and availability comparatively with the alcohol [54], or the alcohol if the criteria of high supply and low cost are applicable to it. 
The latter situation could be applied to glycerol, given the abovementioned glut of this compound [52]. The overall reaction for glycerol esterification is a three-step mechanism for producing mono-, di- and triacetin with one, two and three acyl groups, respectively. The mechanism for the reaction of glycerol with acetic acid with an acid catalyst, basically consists of a first protonation promoted by the acid catalyst on the oxygen electronic pair of the acetic acid, followed by a succession of nucleophilic attacks on the glycerol hydrophilic group to produce MAG and water. MAG in a second stage can react with a new electrophilic molecule of acetic acid to produce DAG and water, and thereafter diacetin can react with a third acetic acid molecule to give TAG, the compound with three acyl groups. MAG formation is not dependent on catalysts, but its presence is fundamental for the optimization of these reactions towards selectivity for production of the three acetins and increasing the reaction rate. Three moles of water molecules are formed as by-products of the three acetylation reactions $[14,51,55]$.

Ion exchange resins are the conventional and industrially preferred catalysts for glycerol acetylation [14]. The acid exchange resins Amberlyst 15 and Amberlyst 35 have been shown to be very efficient catalysts for glycerin acetylation, with a significant recycling capacity of the latter without loss of catalytic activity [51,54]. An ionic exchange resin is an insoluble polymeric matrix, ordinarily consisting of polystyrene-divinylbenzene copolymers, and adsorbed labile ions which can be exchanged with others in the surrounding medium [56,57]. Ion exchange resins can also have a matrix of sulfonated cross-linked polystyrene [52,58]. Depending on the cross-linkage, which is defined as the percentage of divinylbenzene in the resin, those resins are defined as gel-type or macro-reticular type if cross-linkage is below or higher than $12 \%$, respectively. Gel-type resins are uniform microporous structures. They are deformable, rigid not deformable and exhibit a spherical shape which can be adjusted during the synthesis. These materials are only catalytically active in reaction media where the solvent or the reagents are capable of promoting matrix swelling [56,59]. Macroporous resins consist of agglomerates of very small microspheres interspersed with macropores. The permanent porosity, composed of channels between the agglomerates, allows these materials to be effective in both polar and non-polar solvents $[56,57,60]$.

Ion exchange resins can be used as catalysts in innumerable reactions both in slurry form as in fixed bed reactors. The main drawback of these materials is their low thermal stability and inactivation by irreversible sorption of metals and cations. Temperatures higher than $125-150{ }^{\circ} \mathrm{C}$ can cause desulphonation and breakdown of the active sites. Also, catalyst deactivation is dependent mainly on the poisoning effect of iron that is often present as an impurity in the fatty acids used as feedstocks. The poisoning effect observed could be attributed to fouling phenomena derived from the raw nature of the feed and to irreversible adsorption of metals, also present in the feedstock, that deactivate the catalytic acid sites of the resin [61]. Experimental essays, at $105^{\circ} \mathrm{C}$ and atmospheric pressure, of two ionic exchange resin catalysts, Amberlyst-15 (A15) and Dowex 50W*2 (D2), macro-a reticular and gel type, respectively, with styrene and divinylbenzene composition and functionalized with sulphonic groups, showed the good performance of these materials for glycerol acetylation. The experiments were carried out under a high molar ratio of glycerol to acetic acid of 8 [52] so that, as mentioned above, the reaction equilibrium should shift towards product formation. The acetic acid conversions with both catalysts were of $95 \%$. A15 and D2 were submitted to recyclability tests consisting of four sequential reactions of two halves of $20 \mathrm{~min}$. and $4 \mathrm{~h}$ duration times, respectively, applied to both catalysts that showed maintenance of the catalytic activity. Various heterogeneous solid catalysts for carboxylation and acetylation can be used up to four times and deactivation is due to the loss of reactive centers. This loss could be ascribed to factors such as catalyst deactivation due to polar micro-variations in the reaction medium, which can occur for example in the glycerol acetylation with acetic acid, reduced surface area due to mechanical usage, carbon deposition in active centers of the catalyst or leaching of active functional groups on the catalyst surface $[14,62,63]$.

In this glycerol acetylation scheme, catalytic activity should preferably be heterogeneous, due to the presence of active sites on the solid surface. Homogeneous catalysis, due to species leached from the surface catalyst to the reaction medium, is inconvenient insofar that it leads to 
the contamination of the reaction product and disables the reuse of the solid surface [52]. The tests performed by Rodríguez et al. [52] for evaluation whether homogenous catalysis due to leached species was significant, showed clearly the absence of homogeneous catalysis for both products. The optimal catalyst loading was $6.25 \mathrm{~g}$ of dry catalyst per liter of glycerol [52]. Above this threshold, no significant acetic acid conversion gains were obtained. An increase in acetic acid was noticed, though, with an increase of $2.5 \mathrm{~g} / \mathrm{L}$ till $6.25 \mathrm{~g} / \mathrm{L}$. The rationale for this is that a higher amount of catalyst means a higher availableness of active sites, enabling the protonation of more molecules of acetic acid. Thereby the use of lower quantities of catalyst would be reflected on longer reaction times, but once the optimal loading threshold was reached the overloading of catalyst would be a loss of material without increasing the reaction rate. The two ion resin exchange catalysts in the experiments of Rodríguez et al. [52] showed, as expected, a better performance with a drying pretreatment, reflecting the fact that the presence of water hinders the catalysis due to factors such as a lower availableness of acid sites occupied by water molecules or even an eventual hydrolysis of formed esters. Experimentation with hydration showed, as expected, a better catalytic performance of the D2 gel type, due to its reduced cross-linkage, with that performance lowering oppositely with the amount water added to both catalysts. Nevertheless, the acetic acid conversion in glycerol acetylation was always higher with both catalysts, than without none of them, even with a ratio of water to acetic acid of 2. Montmorillonites which are silica layered minerals and niobic acid are other catalysts used in glycerol acetylation. In another experiment [51], A15 allowed obtaining glycerol conversion rates of $97 \%$ after $30 \mathrm{~min}$. with a selectivity of $54 \%$ to diacetin, $31 \%$ to monoacetin and $13 \%$ to triacetin. A $100 \%$ TAG selectivity was achieved was obtained at laboratory scale in glycerol esterification with acetic anhydride at $60{ }^{\circ} \mathrm{C}$, with A-15 and K10-montmorillonite catalysts [64]. This is a relevant result since TAG is a fuel additive necessary for pollution reduction. Some zeolites like HZSM-5 and HUSY can show low-performance catalysis in glycerol acetylation due to problems associated with diffusion and acid site deactivation. The effect of operative variables such as temperature, catalyst loading, reaction time and molar ratios between reagents or of interactions between them, is a determinant of the efficiency of the catalyst supplied and, from the above mentioned, the degree of this influence changes with the specific reaction conditions $[51,64]$.

Another option, proposed by a study of Kale et al. [65], to remove water as a stoichiometric reaction of acetylation, to shift equilibrium reaction towards the product side, triacetin, was an azeotropic distillation scheme. This operation included toluene as an entrainer that should permanently extract the stoichiometric water by-product, from the three step mechanism mentioned above, over acidic ion-exchange resins A15 and Amberlyst 70 (A70). Both the catalysts A15 and A70, which operated, through its Brønsted acid sites, as first proton adders to the carbonyl oxygen of acetic acid, under the aforementioned reaction mechanism, showed the best performance after complete conversion of glycerol with selectivity to triacetin higher than $95 \%$. The fast glycerol conversion and high selectivity to triacetin was due the acidity of catalysts and of water extraction (kinetic and thermodynamic effects). Indeed, in the presence of water maintained by parallel reflux trial, the selectivity to TAG was small.

Under this reactive scheme, toluene forms an azeotropic mixture with water as by-product at $84^{\circ} \mathrm{C}$ and with acetic acid at $104{ }^{\circ} \mathrm{C}$ [66]. Thereby the two azeotopic mixtures may coexist, determining the boiling point of the mixture in dependency of their mass concentrations. At the beginning of the experiment, the reaction rate was high and the mixture started to boil at $100{ }^{\circ} \mathrm{C}$, removing water. As the reaction proceeded, the operative temperature increased and stabilized for $105^{\circ} \mathrm{C}$, for the main time interval. The final temperature of $110^{\circ} \mathrm{C}$, which is the boiling point of toluene, was achieved after a large fraction of the reactant acetic acid, a reactant, was consumed. Removal of unreacted acetic acid, which should be averted, could happen in contingency with the reaction progress and with water removal. The study showed the advantages of acid-catalyzed, water free reaction with an excess of acetic acid in glycerol acetylation. 


\section{Glycerol Reforming}

\subsection{Fundamentals}

A third possible pathway for diminishing the production cost of biodiesel would be to use its main by-product glycerol to produce $\mathrm{H}_{2}$ or syngas through steam reforming. Hydrogen with a high energy yield of $122 \mathrm{MJ} \mathrm{kg}^{-1}, 2.75$ times greater than hydrocarbon fuels, can be seen as a clean fuel without greenhouse gas effect emissions promptly used in fuel cells for the generation of electricity [67]. Currently, about $90 \%$ of the hydrogen is produced from non-renewable carbonaceous raw materials, from which about $48 \%$ of the global hydrogen is produced through the steam reforming of methane, $30 \%$ from coal gasification, and $8.9 \%$ from electrolysis [68]. Compared to other compounds such as methanol and ethanol, glycerol steam reforming [69] can produce higher amounts of hydrogen. Nowadays, hydrogen is considered a potentially valid energy carrier in energy systems, and its demand should increase significantly in the future, due to the technological upgrading of the fuel cell industry. The use of hydrogen in fuel cell systems causes very low atmospheric emission of carbon and no emissions of other pollutants such as nitrogen and sulphur oxides.

Glycerol steam reforming (GSR) provides a possibility of using current steam reforming units for converting glycerol. This is the very reason why glycerol steam reforming has been given high importance, compared to other processes for converting glycerol into hydrogen such as supercritical water reforming [70], or aqueous phase reforming [71]. The high energetic requirements for vaporization of the reaction mixture, reduces the energetic efficiency of GSR, but nevertheless, a huge amount of water is needed to optimize the gasification of carbon, preventing its deposition as coke on the catalyst. The formation of coke is also an issue since it deactivates the catalyst, thus affecting $\mathrm{H}_{2}$ yield and purity.

The molar glycerol/water ratios used in lab studies range between $1 / 6$ and $1 / 9$. The best results in the laboratory are obtained at a temperature in the range of $525-575{ }^{\circ} \mathrm{C}$. However, these are temperature ranges wherein the complex process controls are burdened with an increase in operating costs, energy consumption, an material cost for the reactors. Regarding hydrogen production towards the reforming process, the catalysts are essentially responsible for lowering the activation energy, thus favoring the reaction kinetics. To enhance the productivity and cost-effectiveness of the reaction, the catalysts used in the reforming processes should be highly active as well as stable, generating the smallest possible amount of coke, be sintering-resistant, while avoiding the occurrence of undesirable parallel reactions like methanation or Fischer-Tropsch synthesis. The water-gas-shift reaction (WGS) can occur when a reactant molecule is exposed to specific conditions, such as available active sites, contact with a water molecule for a given period of time and sufficient energy to overcome the activation energy barrier. The fulfillment of these conditions is dependent on operative factors such the flow rate of reagents insofar that it should be only fast enough.

GSR for hydrogen production proceeds according to a complex equation system equilibrium-limited process [72-74]. The two most significant reactions, corresponding to the decomposition of glycerol, and WGS, respectively, are the following:

$$
\begin{gathered}
\mathrm{C}_{3} \mathrm{H}_{8} \mathrm{O}_{3}(\mathrm{~g}) \stackrel{\mathrm{H}_{2} \mathrm{O}}{\leftrightarrow} 3 \mathrm{CO}(\mathrm{g})+4 \mathrm{H}_{2}(\mathrm{~g})\left(\Delta H_{r}^{298 \mathrm{~K}}=251 \mathrm{~kJ} \mathrm{~mol}^{-1}\right) \\
\mathrm{CO}(\mathrm{g})+\mathrm{H}_{2} \mathrm{O}(\mathrm{g}) \leftrightarrow \mathrm{CO}_{2}(\mathrm{~g})+\mathrm{H}_{2}(\mathrm{~g})\left(\Delta H_{r}^{298 \mathrm{~K}}=-41 \mathrm{~kJ} \mathrm{~mol}^{-1}\right)
\end{gathered}
$$

Besides the common products, there are other products resulting from side equations such as carbon dioxide, methane, ethylene, acetic acid, acetone, methanol, formaldehyde, water or coke [75]. For maximizing hydrogen production and avoid methane formation or coke deposition, results from thermodynamical calculations suggest that the GSR should be performed at temperatures of about $627^{\circ} \mathrm{C}$, with steam to glycerol ratios higher than 9 and an operative pressure of $101.3 \mathrm{kPa}[73,74]$. However, as complement for these reforming reactions, WGS is needed to convert the side product $\mathrm{CO}$ to $\mathrm{CO}_{2}$. The implementation of WGS, with its equilibrium wittingly shifted to the right side was 
fundamental for improving hydrogen selectivity of GSR [76]. Also, the available thermodynamic evidence points to the circumstance that steam reforming of oxygenated molecules with $\mathrm{C} / \mathrm{O}$ ratios of one, like glycerol, can occur under temperatures $200-400{ }^{\circ} \mathrm{C}$ lower, compared to alkanes with a similar number of carbon atoms $[77,78]$. This evidence suggests that the reforming of glycerol and water gas shift could occur at a range of temperatures between $127^{\circ} \mathrm{C}$ and $227^{\circ} \mathrm{C}$ [79]. The overall reaction of GSR reform is obtained from the equations above:

$$
\mathrm{C}_{3} \mathrm{H}_{8} \mathrm{O}_{3}(\mathrm{~g})+3 \mathrm{H}_{2} \mathrm{O}(\mathrm{g}) \leftrightarrow 7 \mathrm{H}_{2}(\mathrm{~g})+3 \mathrm{CO}_{2}(\mathrm{~g})\left(\Delta \mathrm{H}_{r}^{298 \mathrm{~K}}=128 \mathrm{~kJ} \mathrm{~mol}^{-1}\right)
$$

The global reaction for GSR is potentially attractive, insofar as the molecular ratio of hydrogen to glycerol is 7. Also, GSR is an endothermic, high operation cost reaction, evolving towards products with an rise of the number of moles and thereby favored by low pressure and high temperatures [13,73], but if the two reactions occur in the same reactor, the hydrogen purity is reduced by the formation of substantial amounts of methane and carbon dioxide. Indeed, along with the reaction above, secondary or side reactions can occur, such as the formation of methane through methanation or glycerol hydrogenolysis or methanol steam reforming:

$$
\begin{gathered}
\mathrm{CO}+3 \mathrm{H}_{2} \leftrightarrow \mathrm{CH}_{4}+\mathrm{H}_{2} \mathrm{O}\left(\Delta H_{r}^{298 \mathrm{~K}}=-206 \mathrm{~kJ} \mathrm{~mol}^{-1}\right) \\
\mathrm{CO}+4 \mathrm{H}_{2} \leftrightarrow \mathrm{CH}_{4}+2 \mathrm{H}_{2} \mathrm{O}\left(\Delta H_{r}^{298 \mathrm{~K}}=-165 \mathrm{~kJ} \mathrm{~mol}^{-1}\right) \\
\mathrm{C}_{3} \mathrm{H}_{8} \mathrm{O}_{3}+4 \mathrm{H}_{2} \leftrightarrow \mathrm{CH}_{4}+2 \mathrm{H}_{2} \mathrm{O}\left(\Delta H_{r}^{298 \mathrm{~K}}=-160 \mathrm{~kJ} \mathrm{~mol}^{-1}\right) \\
\mathrm{CH}_{4}+\mathrm{H}_{2} \mathrm{O} \leftrightarrow \mathrm{CO}+3 \mathrm{H}_{2}\left(\Delta H_{r}^{298 \mathrm{~K}}=-206 \mathrm{~kJ} \mathrm{~mol}^{-1}\right)
\end{gathered}
$$

Additional undesirable side reactions lead to coke or carbon formation in the steam reforming process [80] are:

$$
\begin{gathered}
2 \mathrm{CO}(\mathrm{g}) \leftrightarrow \mathrm{CO}_{2}(\mathrm{~g})+\mathrm{C}(\mathrm{s}) \\
\mathrm{CH}_{4}(\mathrm{~g}) \leftrightarrow 2 \mathrm{H}_{2}(\mathrm{~g})+\mathrm{C}(\mathrm{s}) \\
\mathrm{CO}(\mathrm{g})+\mathrm{H}_{2}(\mathrm{~g}) \leftrightarrow 2 \mathrm{H}_{2} \mathrm{O}(\mathrm{g})+\mathrm{C}(\mathrm{s}) \\
\mathrm{CO}_{2}(\mathrm{~g})+2 \mathrm{H}_{2}(\mathrm{~g}) \leftrightarrow 2 \mathrm{H}_{2} \mathrm{O}(\mathrm{g})+\mathrm{C}(\mathrm{s})
\end{gathered}
$$

Thereby an excessive allocation of water is needed for optimizing the carbon gasification, avoiding thereby its deposition as coke on the catalyst, which inhibits the catalyst, thus affecting $\mathrm{H}_{2}$ yield and purity. More side reactions can occur $[77,81,82]$, with the additional formation of the aforementioned compounds. The $\mathrm{CO}_{2}$ concentration in flue gas increases with temperature, due to the inhibition of the exothermic sorption of $\mathrm{CO}_{2}$, but the effect of temperature increase on $\mathrm{CO}$ concentration is higher, by decreasing of the equilibrium constant of WGS, and thereby the increase in CO concentration with temperature is higher than the corresponding increase in $\mathrm{CO}_{2}$. Methane concentration decreases with an increase in temperature, as expected, but, at temperatures lower than $575{ }^{\circ} \mathrm{C}$, methane is the main impurity in the GSR output, mainly at very small steam/glycerol (hereafter, S/G) ratios (say 3), due to a significant glycerol pyrolysis occurring in parallel to its reforming [79]. Above the threshold of $575^{\circ} \mathrm{C}$, the major impurities in hydrogen were $\mathrm{CO}$ and $\mathrm{CO}_{2}$. The higher purity in hydrogen occurred below $550{ }^{\circ} \mathrm{C}$, due to inhibition of methane formation by sufficient steam, under $\mathrm{S} / \mathrm{G}$ ratios higher than $3[73,79,80]$.

The addition of $\mathrm{a} \mathrm{CO}_{2}$ adsorbent, such as solid $\mathrm{CaO}$, removes carbon dioxide along with the reforming reaction and shifts the WGS reaction equilibrium towards hydrogen production, enhancing thereby the hydrogen yield and purity of GSR. By this technique, side reactions such as $\mathrm{C}$ formation or methanation are almost totally suppressed [83]. The removal of carbon dioxide with $\mathrm{CaO}$, or dolomite $\left(\mathrm{CaMg}\left(\mathrm{CO}_{3}\right)_{2}\right)$, is exothermic, occurring preferentially under lower temperatures:

$$
\mathrm{CaO}(\mathrm{s})+\mathrm{CO}_{2} \leftrightarrow \mathrm{CaCO}_{3}(\mathrm{~s})\left(\Delta H_{r}^{298 \mathrm{~K}}=-178 \mathrm{~kJ} \mathrm{~mol}^{-1}\right)
$$


A new global reaction can be thereby obtained as:

$$
\mathrm{C}_{3} \mathrm{H}_{8} \mathrm{O}_{3}+3 \mathrm{H}_{2} \mathrm{O}+3 \mathrm{CaO}(\mathrm{s}) \leftrightarrow 3 \mathrm{CaCO}_{2}+7 \mathrm{H}_{2}\left(\Delta H_{r}^{298 \mathrm{~K}}=-407 \mathrm{~kJ} \mathrm{~mol}^{-1}\right)
$$

This is an exothermic reaction and the heat delivered can be recovered by physical processes [79]. In this context, one significant technological upgrade is the so-called sorption enhanced glycerol steam reforming (SEGSR), consisting in combining the catalytic glycerol steam reform with $\mathrm{CO}_{2}$ capture in the same equipment. The experimental results of enhanced GSR compare favorably with those from thermodynamic analysis. This process can deliver hydrogen from glycerol with high thermal efficiency and yield. The removal of one product reaction from the reaction medium shifts the thermodynamic equilibrium to the product formation side. The advantages of SEGSR comparatively to GSR are thereby the shift of equilibrium reactions towards higher conversions of glycerol, under analogous operative conditions. The $\mathrm{S} / \mathrm{G}$ ratio is a relevant variable on GSR to evolution of profile of gas product composition $[73,78,79,84]$. Indeed, with other factors remaining constant, a higher ratio (e.g., of the order of 9) is a pre-condition for a high hydrogen yield in the $\mathrm{CO}_{2}$ pre-breakthrough step (see below). With a steam to glycerol ratio of 9 , the gas product composition remains stable with hydrogen concentrations as high as $99 \%$ [79]. For a ratio of 3, the hydrogen molar concentration decreases with time. These yield decreases could be due to carbon deposit build-up on the catalyst, leading to its inactivation, and collected after the recovery of spent catalyst and dolomite from the reactor. Methane is the product gas with higher concentration, due to a bulk of free radical reactions of glycerol pyrolysis.

A discrepancy of experimental and theoretical equilibrium hydrogen concentrations is expected at steam/glycerol ratios of 3, due to an extensive glycerol pyrolysis, contributing to lowering the hydrogen production, and giving side gases such methane and carbon dioxide with deposition of carbonaceous species. Conditions of operational reactivity for glycerol reforming are thereby an operating window at the range $500-750{ }^{\circ} \mathrm{C}$ with a $\mathrm{S} / \mathrm{G}$ ratio of 3 to 9 . A better GSR, without $\mathrm{CO}_{2}$ adsorption, is expected to happen at the higher temperature level. Oppositely, with $\mathrm{CO}_{2}$ capture the maximum hydrogen yield should occur at the lower temperature values. In both systems, the hydrogen yield will increase with the addition of excess steam supplied to the reactor [79]. With glycerol steam reforming, with or without $\mathrm{CO}_{2}$ adsorption the thermal efficiency is highly correlated with the hydrogen yield and improving with the increment of steam-glycerol ratio. For the SEGSR the ideal S/G ratio, yielding the higher thermal efficiency is of 4 , much lower than the one for the process without $\mathrm{CO}_{2}$ removal, although with a smaller hydrogen concentration ratio, than that corresponding to a 9:1 steam to glycerol ratio. The inclusion of a $\mathrm{CO}_{2}$ acceptor in the reaction system, together with a catalyst, induces an equilibrium shift towards the $\mathrm{CO}_{2}$ capture modality, with carbon dioxide removal and also very low amounts of carbon monoxide and methane, together with higher hydrogen content. Due to its labile structure, glycerol is very prone to pyrolysis, considered a cause for restriction of the reforming process, before or after interacting with the catalysts structures. The occurrence of glycerol pyrolysis is very dependent on the reaction temperature and $S / G$ ratio which ascertain the glycerol fraction in the gas phase. The pyrolysis prevailed under the lower temperature, in the chosen temperature window of $500-750{ }^{\circ} \mathrm{C}$, and with $\mathrm{S} / \mathrm{G}$ ratio of 3, lowering thereby the reforming reaction efficiency with methane being the dominant by-product at these lower temperatures. In industry, the SEGSR should be applied with S/G ratios of 4 or higher, for avoiding coke formation and minimizing pyrolysis and methane production. The gas product showed a yield of $99 \%$ of hydrogen, with a S/G ratio of 4 under the $\mathrm{CO}_{2}$ capture regime. The obtainment of pure $\mathrm{H}_{2}$ through the described paths, with very low amounts of other gases, is attractive for power generation through $\mathrm{H}_{2}$ applied in fuel cells $[73,79]$.

One big issue for the implementing of reforming with carbon dioxide removal is the cost of the acceptor utilization. CaO-derived materials downgrade fast after multicarbonation-decarbonation cycle operations. Development of synthetic acceptors with high stability is thereby critical. Minimizing energetic requirements during the acceptor regeneration step is another challenge, and new 
ways for innovation in that issue are the unmixed steam reforming or the autothermal acceptor regeneration $[73,74,79]$.

\subsection{Thermodynamic Analysis}

The common thermodynamic approach to evaluate the yield of hydrogen and other products and the influence of operative variables is performed by the minimization of the Gibbs free energy of the system $[13,79,80,84]$. As mentioned above, given the interconnection and complexity of the framework of chemical reactions involved in GSR for hydrogen production, intermediate byproducts end up in the product stream, reducing the purity of hydrogen delivered. Thermodynamic analysis allows understanding the influence of operative variables such pressure, temperature and $S / G$ ratio. From this analysis, adequate GSR operative modeling can be carried out for maximizing hydrogen yield and minimizing impurities $[80,85,86]$.

Under constant physical conditions ( $\mathrm{P}$ and $\mathrm{T}$ ) of a chemical system, the thermodynamic equilibrium of the system is driven by:

$$
d G=\sum_{i=1}^{k} \mu_{i} d_{n_{i}}
$$

where $G$ is the Gibbs free energy, $\mu_{i}$ is the chemical potential of the component $i$, and $n_{i}$ is the number of moles of component $i$ in the system [74]. The aim is to find the set of $n_{i}$ values which leads to a minimum $G$. This can be addressed through stoichiometric or non-stoichiometric techniques. Under the former, the system is characterized by a set of independent stoichiometric reactions chosen arbitrarily from a set of possible reactions. Under the latter, the equilibrium composition is found through the direct minimization of the Gibbs free energy for a given set of species [87-89]. For the latter methodology, the pointed advantages are that a selection of the possible set of equations is not necessary, no divergence occurs during the computation, and no accurate estimation of initial equilibrium composition is needed.

The general objective function, integrating the variables $P$ and $r$ and the gas constant $R$, which must be numerically minimized, leading to the lowest Gibbs' free energy, is of the kind [74,85]:

$$
G=\sum_{1=1}^{K} n_{i} \Delta G_{i}^{\mathrm{O}}+R T \sum_{i=1}^{K} n_{i} \ln P+R T \sum_{i=1}^{K} n_{i} \ln y_{i}
$$

where for the $i$ th species, $y_{i}$ is the mole fraction, $G_{i}^{\mathrm{O}}$ is the standard Gibbs free energy of formation. The condition that must satisfied is that $n_{i}$ values must satisfy the elemental mass balance:

$$
\sum_{i=1}^{K} a_{l i} n_{i}=b_{l}, l=1, \ldots, M
$$

where in $a_{l i}$ and $b_{l}$ are the number of gram-atoms of element $l$ on a mole of species $i$ and $b_{l}$ is the total number of grams of atoms of element $i$ in the reaction mixture.

Calculations implemented in mathematical digital packages, based on techniques of constrained optimization through sequential quadratic programming methodology, complemented with numerical finite differences to estimate the gradient of the objective function or on Lagrange multiplier solver can provide accurate estimates for hydrogen yields and for the influence of operative parameters [86]. Adhkari et al. [80] made this modeling analysis for estimating hydrogen production by simple GSR, without optimizing effects due to removal of reaction products or the catalysts effects, with a variation of system pressure in the range of $101.3 \mathrm{kPa}-506.51 \mathrm{kPa}$, system temperature ranging between $327^{\circ} \mathrm{C}$ and $727^{\circ} \mathrm{C}$, and S/G ratio in the range 1-9. The considered products for GSR were hydrogen, methane, carbon monoxide, carbon dioxide, unreacted water, glycerol and carbon. The chemical elements $\mathrm{C}$, $\mathrm{H}$ and $\mathrm{O}$ were common to all compounds and thereby were considered for the mass balance.

The total Gibbs free energy was considered as independent of $C$, since the free energy of $C$ formation is null. The numerical results showed that hydrogen molar yield increased with temperature, and for a given temperature, also increased with the $S / G$ ratio. For every operative temperature, 
higher excess of hydrogen is produced with excess water in the system. The molar fraction of hydrogen produced is directly correlated with the $\mathrm{S} / \mathrm{G}$ ratio, increasing and decreasing with this ratio. Indeed the excess water existent at higher ratios, reduces the molar fraction of a given absolute quantity of hydrogen. The best theoretical hydrogen output was 6 hydrogen moles per mole of glycerol, comparing with a stoichiometric value of 7 , at $627^{\circ} \mathrm{C}$ and atmospheric pressure. The number of moles of $\mathrm{H}$ and $\mathrm{CO}_{2}$ decreases at temperatures above $687^{\circ} \mathrm{C}$, simultaneously with the increase of $\mathrm{CO}$ and water vapor. Also the molar yield of hydrogen increase with decreasing system pressure, which is expected from the global GSR above. Concerning methane production, an undesirable product for hydrogen production through GSR, the calculations showed that molar yield of $\mathrm{CH}_{4}$ decreased with increases in temperature and $S / G$ ratios. Higher system pressures favored methane production. At higher steam to glycerol ratios (e.g., 9) and temperatures higher than $680{ }^{\circ} \mathrm{C}$, the formation of methane was almost inhibited. This should be due to the energy release of methane oxidation, according to the reactions:

$$
\begin{gathered}
\mathrm{CH}_{4}(\mathrm{~g})+2 \mathrm{H}_{2} \mathrm{O}(\mathrm{g}) \leftrightarrow \mathrm{CO}_{2}(\mathrm{~g})+4 \mathrm{H}_{2}(\mathrm{~g}) \\
\mathrm{CH}_{4}(\mathrm{~g})+\mathrm{H}_{2} \mathrm{O}(\mathrm{g}) \leftrightarrow \mathrm{CO}(\mathrm{g})+3 \mathrm{H}_{2}(\mathrm{~g})
\end{gathered}
$$

However, also at a low $\mathrm{S} / \mathrm{G}$ ratio, for instance, 1, the methane formation was shown as very small, probably due to carbon formation. The number of $\mathrm{CO}$ moles also increased with temperatures, from 0 moles at $327^{\circ} \mathrm{C}$ till a range of 1.2 to 2.5 moles at $727^{\circ} \mathrm{C}$. For a given temperature, the number of $\mathrm{CO}$ moles also increased with $\mathrm{S} / \mathrm{G}$ ratios. Concerning the number of $\mathrm{CO}_{2}$ moles, the calculation results showed an increase in $\mathrm{S} / \mathrm{G}$ ratio and with temperature, till a peak of $2.3 \mathrm{CO}_{2}$ moles was reached at a temperature of about $560{ }^{\circ} \mathrm{C}$, followed by a decrease at higher temperatures. The carbon formation in GSR as coke is highly undesirable for an efficient GSR. At $730{ }^{\circ} \mathrm{C}$, under any $\mathrm{S} / \mathrm{G}$ ratio, no carbon is formed [74]. Also, S/G ratios of 6 to 9 prevent coke formation, insofar that an increase of the same ratio from 1 to 3 is enough to reduce carbon deposition significantly.

The global thermal efficiency of GSR is an important variable to be considered on the technical and economic feasibility of the operation. When GSR is processed without capture of carbon dioxide the thermal efficiency, $\eta_{\mathrm{SR}}$, of the system is given by [79]:

$$
\eta_{\mathrm{SR}}=\frac{\eta_{\mathrm{H}_{2}} \mathrm{LHV}_{\mathrm{H}_{2}}}{\eta_{\mathrm{Gly}} \mathrm{LHV}_{\mathrm{Gly}}+H_{\mathrm{out} T}-H_{\mathrm{in} T}+\eta_{\text {steam }} \Delta H_{\text {latent }}} \times 100
$$

where $\eta_{\mathrm{H}_{2}}$ is the molar yield of produced hydrogen $\eta_{\mathrm{Gly}}$ is the molar input of glycerol, $\mathrm{LHV}_{\mathrm{H}_{2}}$ is the low heating value of hydrogen and $\mathrm{LHV}_{\mathrm{Gly}}$ is the low heating value of glycerol, $\eta_{\text {steam }}$ is the steam molar input, $\Delta H_{\text {latent }}$ refers to latent heat of fed steam and $H_{\text {out } T}$ and $H_{\text {in } T}$ are the enthalpies, at temperature $T$ of the reaction system, of output and input streams. If the enhanced sorption is considered, then the energy budget should include the heat required for regenerating the carbon dioxide receptor, $\Delta H_{\text {reg, }}$, according with the following reaction:

$$
\mathrm{CaCO}_{3}(\mathrm{~s}) \leftrightarrow \mathrm{CaO}(\mathrm{s})+\mathrm{CO}_{2}\left(\Delta H_{\mathrm{reg}}^{298 \mathrm{~K}}=178 \mathrm{~kJ} \mathrm{~mol}^{-1}\right)
$$

The equation for thermal efficiency with enhanced reforming, $\eta_{\text {SRER }}$, becomes:

$$
\eta_{\mathrm{SRER}}=\frac{\eta_{\mathrm{H}_{2}} \mathrm{LHV}_{\mathrm{H}_{2}}}{\eta_{\mathrm{Gly}} \mathrm{LHV}_{\mathrm{Gly}}+H_{\mathrm{out} T}-H_{\mathrm{inT}}+\eta_{\text {steam }} \Delta H_{\text {latent }}+\Delta H_{\text {reg }}} \times 100
$$

\subsection{Experimental Approach}

\subsubsection{General Case Study}

The hydrogen selectivity in GSR can be optimized through the use of catalysts. Under temperatures higher than $400{ }^{\circ} \mathrm{C}$, a full glycerol conversion with a high $(>85 \%)$ selectivity for 
hydrogen was obtained with Ir, Co and Ni catalysts supported with cerium oxide [90]. Also, a 3 wt \% $\mathrm{Ru} / \mathrm{Y}_{2} \mathrm{O}_{3}$ catalyst showed high performance for GSR withstanding carbon deposition in a long-term. An alternative pathway for a hydrogen production, from $\mathrm{C}_{2}$ to $\mathrm{C}_{6}$ compounds with oxygen, involves the generation of hydrogen and $\mathrm{CO}$ resulting from the cleavage of $\mathrm{C}-\mathrm{C}$ chemical connections, continued by the WGS reaction leading to $\mathrm{CO}_{2}$ and hydrogen from $\mathrm{CO}$ [77]. An adequate catalyst should thereby perform well on the $\mathrm{C}-\mathrm{C}$ cleavage and also on the WGS reaction. From results with steam reforming of ethanol, a congener alcohol, the cobalt-nickel/hydrotalcite-like catalysts have shown to be adequate for GSR.

For increasing the production of $\mathrm{H}_{2}$ through GSR the catalyst agent should catalyze the breakage of $\mathrm{C}-\mathrm{C}, \mathrm{O}-\mathrm{H}$ and $\mathrm{C}-\mathrm{H}$ chemical bonds in the hydrocarbon reacting with oxygen, leading to $\mathrm{H}_{2}$ and $\mathrm{CO}_{2}$, and also catalyze the WGS reaction to remove absorbed $\mathrm{CO}$ as $\mathrm{CO}_{2}$ [91]. Thermodynamic evaluation indicated that 7 moles of hydrogen can be produced from SEGSR, by removing $\mathrm{CO}_{2}$ as mentioned above, at ratios of S/G higher than 9 and an operative pressure of $101.3 \mathrm{kPa}$. On the other hand, experimental analysis corroborated that SEGSR allow achieving a slight lower $\mathrm{H}_{2}$ yield than the predicted from thermodynamic results $[92,93]$ with purity above $90 \%$.

Therefore the challenges to cope with in the optimization of GSR reactions are the selection of a suitable catalyst which must address issues such as the reactions of enhanced GSR, the steam reforming of light released hydrocarbons such as methane, the operative temperature, and S/G ratio. To achieve economic viability of $\mathrm{H}_{2}$ obtained from GSR, a recycling of the $\mathrm{CO}_{2}$ acceptor is fundamental, through carbonation/decarbonation reactions occurring with the steam reforming and regeneration steps [73,79].

One representative case study for addressing the issues linked with the experimental performing of catalyzed GSR with and without $\mathrm{CO}_{2}$ is given, e.g., by He et al. [79]. Under that experimental scheme, GSR was performed with a cobalt-nickel/hydrotalcite(Co-Ni/HTIs)-like catalyst prepared according to $\mathrm{He}$ et al. [94], with calcined dolomite as a $\mathrm{CO}_{2}$ acceptor. Calcined dolomite is a CaO-based acceptor with good competitive aptitude and kinetics for optimizing hydrogen release [74,95]. A reactant aqueous solution mixture was prepared and added for obtain several S/G ratios $(3,4$, or 9$)$ and stored in a tank. All reactions were performed in a tube fixed bed reactor at $101.3 \mathrm{kPa}$. Mass flows were continuously monitored. The catalyst to dolomite (C/D) ratio was varied $(1: 10 ; 2: 10 ; 5: 2.5)$ in distinct essays to verify the effects of $\mathrm{CO}_{2}$ removal on $\mathrm{H}_{2}$ production and to change the breakthrough time. The catalyst was activated, before the GSR reactions, by reducing metal oxides, with a flowing gas of $50 \% \mathrm{H}_{2}$, mixed with $50 \% \mathrm{Ar}$, at $670{ }^{\circ} \mathrm{C}$, during $10 \mathrm{~h}$. The GSR reactions were initiated after purging and quenching the reactor during $1 \mathrm{~h}$ with $\mathrm{Ar}$, to the appropriate temperature. The liquid reactant blend flowing at $5 \mathrm{~g} \cdot \mathrm{h}^{-1}$ was brushed by Ar flowing at $25 \mathrm{~mL} \cdot \mathrm{min}^{-1}$ and directed into a pre-heater at $400{ }^{\circ} \mathrm{C}$ and thereafter fed into the reactor. A continuous flow of $\mathrm{N}_{2}$, at a rate of $21 \mathrm{~mL} \cdot \mathrm{min}^{-1}$, into the reactor served as an internal standard. The SEGSR occurs until the calcined dolomite as $\mathrm{CO}_{2}$ acceptor saturated, losing thereby its aptitude for $\mathrm{CO}_{2}$ extraction. After that the conventional steady GSR took place. Comparative lab essays were carried out for comparing GSR with SEGSR performances. Also, the saturated acceptor was randomly regenerated by submission to $770{ }^{\circ} \mathrm{C}$ during $30 \mathrm{~min}$, under Ar gas flow at $100 \mathrm{~mL} \cdot \mathrm{min}^{-1}$. Thereafter the product gas from the reactor was cooled, and its moisture extracted by physical drying. The exiting gaseous mix was continuously analyzed through adequate instrumentation, and the calculation of component product fractions was on a water-free basis. The released gases are $\mathrm{H}_{2}, \mathrm{CH}_{4}, \mathrm{CO}, \mathrm{CO}_{2}$ ethane and ethane, wherein the first four prevailed. The theoretically maximum stoichiometric 7 moles for $\mathrm{H}_{2}$ formation from the GSR process was taken as a standard for evaluating the actual hydrogen yield.

A thermodynamic evaluation of $\mathrm{H}_{2}$ delivering and thermal efficiency, as above described, was performed with theoretical evaluation of equilibrium composition and minimizing of Gibbs free energy in compliance with other analogous works $[74,78,88,96]$. The reactants are $\mathrm{H}_{2} \mathrm{O}$, glycerol, and $\mathrm{CaO}$, with the condition that $\mathrm{CaO} /$ glycerol molar ratio should be 3 . To better compare SEGSR with conventional GSR, a specific analysis was also done, without considering $\mathrm{CaO}$ as reactant. 
Other products besides hydrogen, methane, $\mathrm{CO}, \mathrm{CO}_{2}$, and $\mathrm{CaCO}_{3}$ to be considered as product reagents are solid carbon, high boiling organic compounds, and heavy hydrocarbons. The operative conditions were pressure and temperatures ranging between $101.3 \mathrm{kPa}$ and $2026 \mathrm{kPa}$, and $500{ }^{\circ} \mathrm{C}$ and $850{ }^{\circ} \mathrm{C}$, respectively and $\mathrm{S} / \mathrm{G}$ ratios of 3,4 and 9 .

A S/ $\mathrm{G}$ ratio of 3, gave a low $\mathrm{H}_{2}$ production on the process without $\mathrm{CO}_{2}$ capture. Notwithstanding the increasing of $\mathrm{H}_{2}$ production with the temperature, the maximum $\mathrm{H}_{2}$ production was only about $70 \%$ of the theoretical limit. Oppositely, a hydrogen yield higher than $80 \%$ was obtained with the SEGSR, specifically in the temperature ranges below $650{ }^{\circ} \mathrm{C}$. At superior temperatures, the $\mathrm{CaO}$ acceptor was saturated and $\mathrm{CO}_{2}$ adsorption was lowered. At temperatures above $750{ }^{\circ} \mathrm{C}$ there was no difference in the $\mathrm{H}_{2}$ production between SEGSR and GSR, because the $\mathrm{CO}_{2}$ removal from the gas flow is suppressed due to the exothermic character of $\mathrm{CO}_{2}$ fixation by $\mathrm{CaO}$. Steam is commonly used in GSR at amounts above the stoichiometric limit for increasing the hydrogen yield and preventing coking. For an S/G ratio in the range 3-9, the $\mathrm{H}_{2}$ production of the traditional GSR reached an upper limit $85 \%$ at $650{ }^{\circ} \mathrm{C}$. On the other hand, at temperatures below $600{ }^{\circ} \mathrm{C}$, the maximum stoichiometric yield of 7 moles (or 100\%) of $\mathrm{H}_{2}$, per mole of glycerol, was reached through $100 \% \mathrm{CO}_{2}$ extraction at a $\mathrm{S} / \mathrm{G}$ ratio of 9 .

The thermal efficiency of the SEGSR is highly correlated with hydrogen productivity and thereby the calculated thermal efficiency of the SEGSR declines as the operative temperature rises. The addition of steam to increase the $S / G$ ratio implies a huge energy loss because, in practice, the latent heat of stem is not easy to retrieve. The $\mathrm{H}_{2}$ obtained by SEGSR can balance the additional energetic cost for producing extra steam.

As mentioned above, for a given temperature, the thermal efficiency of GSR rises with the rise of $\mathrm{S} / \mathrm{G}$ ratio. This latter consideration is particularly valid for temperatures below $700{ }^{\circ} \mathrm{C}$. In this case study, the thermal efficiency of GSR has risen from 53 to $69 \%$, as the S/G ratio rose from 3 to 9 at $600{ }^{\circ} \mathrm{C}$.

The input of additional steam implies only a slight increase in the thermal efficiency of the SEGSR process. In this case study, the thermal efficiency rose by augmenting the $S / G$ ratio from 3 to 4 . But an additional augment of that ratio, was not reflected on the calculated thermal efficiency [79]. In this case study, the rise in $\mathrm{H}_{2}$ production was not compensated by a gain in energy efficiency, due mainly to additional heating of vapor. The $\mathrm{H}_{2}$ yield and thermal efficiency decreased with the raise of the reactive pressure in the range from 0 to $2026 \mathrm{kPa}$ both to GSR as to SEGSR. However, the former process is more sensitive to pressure increase than the former. This should be related to fact that a pressure rise does not facilitate $\mathrm{H}_{2}$ production, but stimulates methanation reaction and methane generation. This effect is counteracted with a $\mathrm{CO}_{2}$ adsorption increase at high pressures. On the other hand, for a GSR operation carbon formation increases with pressure. Indeed, at a pressure e.g., of 2026 $\mathrm{kPa}$ a high carbon deposition is expected, for all S/G ratios, whilst that for a SEGSR reaction, no carbon is deposited. At atmospheric pressure, carbon formation is suppressed during the reforming operation, either with GSR or with SEGSR. Also, the thermodynamic analysis shows that SEGSR has a low potential to carbon formation, even at $20 \mathrm{~atm}$. operative pressures [79].

This described effect of sorption enhancement of GSR on the improvement of the overall reaction, evaluated through experimental and modeling approaches, reflected on higher hydrogen content and lower yields of $\mathrm{CO}, \mathrm{CO}_{2}$ and $\mathrm{CH}_{4}$, under temperatures ranging between $500{ }^{\circ} \mathrm{C}$ and $620{ }^{\circ} \mathrm{C}$, is demonstrated in the literature [93]. Truly, the selection of an appropriate temperature range for optimizing to benefits of the $\mathrm{CO}_{2}$ sorption enhancement is critical, and experimental evidence suggests the interval of $500-620^{\circ} \mathrm{C}$ as adequate for this purpose. The temperature of $500{ }^{\circ} \mathrm{C}$ seems to an optimum temperature for glycerol steam reforming with $\mathrm{CO}_{2}$ removal, exhibiting the longest $\mathrm{CO}_{2}$ breakthrough time and the highest $\mathrm{H}_{2}$ purity and concentration [97]. In the higher range of this temperature interval, the exothermic water gas shift reaction and $\mathrm{CO}_{2}$ sorption are lowered, whilst the endothermic steam reforming of methane is increased $[73,79,98]$.

The main drawback of this system, as aforementioned, is that the $\mathrm{CO}_{2}$ sorbent saturates and then its regeneration is necessary. A typical scheme for sorbent regeneration, concomitant to SEGSR, is the 
one composed by two moving beds and a cyclone on the top, wherein catalyst and sorbent flow at a velocity of $9-11 \mathrm{~cm} \cdot \mathrm{min}^{-1}$, and a device for ascendant movement which is used for transporting nitrogen with particles of catalyst and sorbent. Losses of particles over the reforming reactions are of about $5 \%$ for every $5 \mathrm{~min}$. are thereby adjusted by injection of particles of catalyst and sorbent on the top $[74,99,100]$.

The different $\mathrm{CO}_{2}$ sorbents are materials such as hydrotalcites, a group of clay minerals with a structure of hydroxide layers [100,101], lithium zirconates or lithium silicates [102-105]. The sorption capacity $(\mathrm{mol} / \mathrm{kg})$ of K-doped hydrotalcite is significantly high $\left(9.4 \mathrm{~mol} \cdot \mathrm{kg}^{-1}\right)$ under wet conditions. Under dry conditions, without the presence of steam, the maximum sorption capacity was $1.8 \mathrm{~mol} \cdot \mathrm{kg}^{-1}$. The charge compensating anion of hydrotalcites also influences the $\mathrm{CO}_{2}$ capture, due to the promotion of increase of Brunauer, Emmet, and Teller (BET) specific surface $\left(114.3 \mathrm{~m}^{2} \cdot \mathrm{g}^{-1}\right)$. Experimental evidences also pointed that after more than 50 operative cycles, potassium hydrotalcites showed no significant decay [106]. Adsorbents like CaO-based materials, lithium zirconates and silicates show generally a lessen $\mathrm{CO}_{2}$ capacity and slowest adsorption kinetics at $300-400{ }^{\circ} \mathrm{C}$, regeneration temperatures above $650{ }^{\circ} \mathrm{C}$ and a moderate inactivation due to sintering of the active surfaces [101]. Their higher adsorbing capacities occur at much higher temperatures (say, $700-850^{\circ} \mathrm{C}$ ). The sintering of $\mathrm{CaO}$ adsorbents can be avoided through the mixing with cetylmethyl ammonium bromide (CTAB) [107]. Also, the carbonation reaction rates of $\mathrm{CaO}$ adsorbents, made with $\mathrm{CTAB}$, exhibited carbonation rates higher by as much as $154 \%$ comparatively to $\mathrm{CaO}$ made without $\mathrm{CTAB}$. Adding yttrium oxide to calcium oxide also improves the carbonation rate and the sorption aptitude of $\mathrm{CaO}$-derived $\mathrm{CO}_{2}$ sorbents [108].

The choice of the $\mathrm{CO}_{2}$ sorbent to be used in the SEGSR reactor is dependent on the operating temperature. Obviously, the temperature reduction is mandatory for the diminishing of production costs and therefore there is a convenience in working at temperatures in the range of $300-500{ }^{\circ} \mathrm{C}$. Under this range of temperatures, hydrotalcites have been reported as having good performance on the kinetics of $\mathrm{CO}_{2}$ adsorption capacities, with a special enhancement of that performance under wet conditions typical of GSR processes $[100,101]$. The sorbent/glycerol ratio is also a relevant variable in GSR. Considering $\mathrm{CaO}$, for example, experimental evidence indicates that the concentration of $\mathrm{H}_{2}$ increases with rising $\mathrm{CaO} /$ glycerol ratios, whilst, under the same conditions, the amounts of $\mathrm{CO}$ and $\mathrm{CO}_{2}$ diminish. Also, a ratio of $\mathrm{CaO} /$ glycerol of 10 is a threshold, beyond which there is no variation of $\mathrm{H}_{2}, \mathrm{CO}, \mathrm{CO}_{2}$ and $\mathrm{CH}_{4}$ concentrations [109].

One adequate system for the GSR should be based on the introduction of a SEGSR in the presence of calcined dolomite as $\mathrm{CO}_{2}$ sorbent, with a Ni-Co/hydrotalcite catalyst. The temporal dynamics of $\mathrm{CO}_{2}$ capture has three stages: pre-breakthrough, breakthrough and post-breakthrough. In the pre-breakthrough regime, over $140 \mathrm{~min}$, most of the $\mathrm{CO}_{2}$ is extracted by a fast carbonation with $\mathrm{CaO}$ thereby increasing the $\mathrm{H}_{2}$ yield. In the breakthrough regime, $\mathrm{H}_{2}$ yield decreases and in the post-breakthrough the sorbent is already saturated, and the $\mathrm{H}_{2}$ yield is steady, controlled by $\mathrm{CO}_{2}$ diffusion under the carbonation reaction $[73,110,111]$. In the latter stage, the SEGSR reactor turns a conventional fixed bed glycerol steam reforming. The highest purity of hydrogen is obtained in the $\mathrm{CO}_{2}$ pre-breakthrough period as expected, with a duration of, say, $140 \mathrm{~min}$ in a total carbonation/decarbonation cycle, under operative temperatures ranging between $400{ }^{\circ} \mathrm{C}$ and $700{ }^{\circ} \mathrm{C}$, with dolomite as a $\mathrm{CO}_{2}$ sorbent. The optimizing effect of enhanced sorption is low at $700{ }^{\circ} \mathrm{C}$, due to carbonate decomposition (calcination). The calcinate dolomite can even react with water vapor steam, reducing thereby the ratio $\mathrm{S} / \mathrm{G}$ in the reactor $[73,93,97]$.

\subsubsection{Case Study about Potential for Reforming Crude Glycerol}

Concerning the direct reforming of crude glycerol (CGLY), some drawbacks exist, related to the purification of hydrogen insofar that the produced hydrogen has about $90 \%$ volume purity, within a mixture of methane and $\mathrm{CO}$, due to the composition of the feedstock. In this context, the direct production of hydrogen with the highest possible purity is highly desirable for simplifying the 
industrial layout and reducing the costs of hydrogen production. Another barrier for the reforming of crude glycerol is the high deposition of carbon and coke, due the existence of bulky compounds like the $\mathrm{C}_{17}-\mathrm{C}_{19}$ acid methyl esters. An excessive coking leads to catalyst inactivation and lowers the hydrogen yield.

Fermoso et al., showed the possibility for using one stage SEGSR as an effective scheme for crude glycerol reform [112]. From the ultimate analysis of the feedstock, the theoretical exothermic reaction of SEGSR for crude glycerol, after combination of WGS with carbonation reactions can be written as:

$$
\mathrm{C}_{3} \mathrm{H}_{8.95} \mathrm{O}_{3.4}+2.6 \mathrm{H}_{2} \mathrm{O}+3 \mathrm{CaO} \leftrightarrow 7.08 \mathrm{H}_{2}+3 \mathrm{CaCO}_{3}, \Delta H=-591 \mathrm{~kJ} \cdot \mathrm{kg}^{-1}
$$

The molar yield of hydrogen is thereby of 7.08 moles of $\mathrm{H}_{2}$ per mole of crude glycerol. Fermoso et al. generalized the single stage SEGSR to the complex framework of crude glycerol, in a reactor having a mixture of $\mathrm{Ni}-\mathrm{CO}$ catalyst obtained from hydrotalcite-like material (HT) and calcinated dolomite as $\mathrm{CO}_{2}$ sorbent. The complexity of crude GSR is reflected by its many products which, besides hydrogen, are, for example, methane, ethane, carbon monoxide methanol, acrolein, allyl alcohol, water or coke.

The HT was prepared by co-precipitation of $\mathrm{Al}\left(\mathrm{NO}_{3}\right)_{3} \cdot 9 \mathrm{H}_{2} \mathrm{O}$ with $\mathrm{Co}\left(\mathrm{NO}_{3}\right)_{3} \cdot 6 \mathrm{H}_{2} \mathrm{O}$, $\mathrm{Mg}\left(\mathrm{NO}_{3}\right)_{3} \cdot 6 \mathrm{H}_{2} \mathrm{O}$ and $\mathrm{Ni}\left(\mathrm{NO}_{3}\right)_{2} \cdot 6 \mathrm{H}_{2} \mathrm{O}$. Co and $\mathrm{Ni}$ corresponded to a $40 \%$ total metal loading, for a material with mass composition $20 \% \mathrm{Ni}-20 \% \mathrm{Co}$ HT. This precipitate was filtered and calcinated to give the Co-Ni catalyst, which showed a BET specific area of $94 \mathrm{~m}^{2} \cdot \mathrm{g}^{-1}$, with an averaged pore size of $6 \mathrm{~nm}$. Before the reforming processes, the $\mathrm{Ni}-\mathrm{Co} / \mathrm{HT}$ catalyst was activated, by reducing metal oxides with a running gas mixture $\mathrm{H}_{2}-\mathrm{N}_{2}$ of $50 \%$ vol. each, with a total stream rate of $200 \mathrm{NmL} \cdot \mathrm{min}^{-1}$ at $670{ }^{\circ} \mathrm{C}$ for $10 \mathrm{~h}$. Thereafter, the reactor was cleansed with $\mathrm{N}_{2}$ and quenched to the operative temperatures ranging between $525^{\circ} \mathrm{C}$ and $600{ }^{\circ} \mathrm{C}$. The attempts occurred at $101.3 \mathrm{kPa}$, and the liquid reactant mix, running at $5-10 \mathrm{~g} \cdot \mathrm{h}^{-1}$, submitted to a gas stream of $15-150 \mathrm{NmL} \cdot \mathrm{min}^{-1}$ of $\mathrm{N}_{2}$, to maintain the ratio $\mathrm{N}_{2} / \mathrm{C}$ constant at 3 . The sorbent/catalyst and the space-time ratios were always kept at $5 \mathrm{~g} / \mathrm{g}$ and $1.09 \mathrm{~h}$, respectively. Space-time ( $\tau=\mathrm{min}$ ) is a variable in GSR, used by some authors, defined as the quotient between the mass of the catalyst (grams) in the reactor and the mass inflow of the reactants $\left(\mathrm{N}_{2}, \mathrm{H}_{2} \mathrm{O}\right.$, and glycerol) in $\mathrm{g} \cdot \mathrm{min}^{-1}$. Space-time ratio is the inverse of space velocity. The SEGSR of crude glycerol were carried out until the $\mathrm{CO}_{2}$ sorbent (calcinated dolomite) was saturated and unable to remove more $\mathrm{CO}_{2}$ from the flow. The combined action of removal of $\mathrm{CO}_{2}$ by dolomite, with the use of the Ni-Co/HT catalyst, enhances the $\mathrm{H}_{2}$ production and WGS reaction. For result comparison, parallel reactions of traditional SR and WGS were also performed. A clear distinction of pre-breakthrough, breakthrough and post breakthrough periods (see below) was shown for SGR and SEGSR processes. The major significant production of hydrogen with a significant removal of $\mathrm{CO}_{2}$ occurs in the first period, as happens with refined glycerol. The results showed a high $\mathrm{C}-\mathrm{C}$ chemical connection break by the Ni-Co catalyst and heavy hydrocarbon reforming reactions. Therefore, high hydrogen purity and selectivity, ranging from 99.1 to $99.9 \%$, and yields between $85 \%$ and $88 \%$ were achieved. The $\mathrm{H}_{2}$ selectivity did not vary with reaction temperature. $\mathrm{CO}$ concentration was reduced with temperature, perhaps due to favorable thermodynamics of WGS at cooler temperatures. The exothermic carbonation and kinetic dynamics were lowered at higher temperatures.

The highest $\mathrm{H}_{2}$ purity $(99.7 \%)$ was achieved at temperatures of $550{ }^{\circ} \mathrm{C}$ and $575{ }^{\circ} \mathrm{C}$. These were also the temperatures corresponding to lower $\mathrm{CO}$ and $\mathrm{CH}_{4}$ concentrations. The high production of $\mathrm{H}_{2}$ from crude glycerol reforming can be due to the presence of $\mathrm{C}_{17}-\mathrm{C}_{19}$ compounds with oxygen, which are favorable to higher enhanced glycerol reforming, through thermodynamic evaluation. The existence of methanol in the liquid mix, could also enhance hydrogen purity, because methanol reforming does not require cleavage of $\mathrm{C}-\mathrm{C}$ bonds, showing thereby a low propensity for methane formation. The effect of variation of space-time, under constancy of all variables, was reflected on the maintenance of high $\mathrm{H}_{2}$ purity, in a high range of 99.5-99.7\%, and by a sharp decrease of $\mathrm{H}_{2}$ yield from 88.1 to $45.3 \%$ as $\tau$ decreased from 1.09 to $0.54 \mathrm{~h}$. The strategy of integrating SEGSR of hydrocarbons and oxygen, WGS and carbonation reaction into a single stage, showed that the production of $\mathrm{H}_{2}$ was reduced 
directly with the diminishing of spatial time, suggesting a much lower reaction rate of CGLY reforming in comparison with these of methane reforming and water-gas shift reactions. Also the reaction rate of WGS and methane reforming were sufficient to maintain the reactions close to equilibrium at the conditions studied and a steady $\mathrm{H}_{2}$ purity. The results also allowed concluding that with CGLY reforming, the break of $\mathrm{C}-\mathrm{C}$ chemical connections was a restrictive step for $\mathrm{H}_{2}$ production.

The hydrogen yield by Fermoso et al. achieved by SEGSR of crude glycerol, ranging between $85 \%$ and $88 \%$, at $\tau=1.09 \mathrm{~h}$ are still lower when compared with yields of $99 \%$ [47], corresponding to SEGSR with refined glycerol, under the same steam/C tratio of 3 . This is associated to deposits of carbonaceous materials from crude glycerol, like coke. This carbon formation is due e.g., to the existance of non-volatile bulky compounds in the CGLY, such as $\mathrm{C}_{17}-\mathrm{C}_{19}$ acid methyl esters and also to a high $\mathrm{Na}$ concentration $(17 \%)$ in the coke, resulting from inorganic salts existing in the CGLY.

A potential for producing $\mathrm{H}_{2}$ with purity $(99.7 \%)$ and yield ( $\left.88 \%\right)$, at acceptable space-time values, from the crude glycerol reforming with SEGSR technology exists, which could avoid expensive options for crude glycerol purifying. Also, the $\mathrm{CO}$ level (100 ppm) existing in the flue $\mathrm{H}_{2}$ gas stream, obtained from CGLY reform, is still a bit high as input for low temperature fuel cells. However high temperature or acid fuel cells can already be used as receptors of this flue $\mathrm{H}_{2}$ stream [113]. Also, the operative philosophy of sorption enhancing reforming of crude glycerol has great potential for conversion of other complex mixtures from biomass, such as bio-oils, for high purity $\mathrm{H}_{2}$ and other forms of clean energy.

\subsubsection{Catalysts}

Catalysts, as mentioned above, are fundamental in controlling the selectivity of GSR. The selection and research of catalysts for GSR have been focused on Group VIII metals. Catalysts adequate for GSR are these which can break $\mathrm{C}-\mathrm{C}, \mathrm{O}-\mathrm{H}$ and $\mathrm{C}-\mathrm{H}$ chemical connections, namely transition metals such as $\mathrm{Pt}, \mathrm{Ni}, \mathrm{Ru}, \mathrm{Ir}, \mathrm{Co}, \mathrm{Re}, \mathrm{Rh}$, and Pd. Some of the most common catalysts for GSR are shown on Table 1. Nickel is the most broadly scrutinized catalyst, because of its inexpensiveness and efficacy in breaking $\mathrm{C}-\mathrm{C}$ bonds in the GSR reactions. Ruthenium is the cheapest of the noble metals and is, along with nickel and platinum, one of the most required chemical elements for use in catalysis of $\mathrm{H}_{2}$ production by GSR. Platinum is also a very effective material for that purpose.

Table 1. Some catalysts for GSR reaction (adapted from Bagnato et al. [13]).

\begin{tabular}{ccccc}
\hline Catalyst Type & Order of Reaction for Glycerol & Order of Reaction for Steam & Ea (kJ/mol) & Refs. \\
\hline $\mathrm{Pt} / \mathrm{C}$ & 1 & - & - & {$[114]$} \\
$\mathrm{Co} / \mathrm{Al}_{2} \mathrm{O}_{3}$ & 0.1 & 0.4 & 67.2 & {$[115]$} \\
$\mathrm{Ni} / \mathrm{Al}_{2} \mathrm{O}_{3}$ & 0.48 & 0.34 & 60.0 & {$[116]$} \\
$\mathrm{Co}-\mathrm{Ni} / \mathrm{Al}_{2} \mathrm{O}_{3}$ & 0.25 & 0.36 & 63.3 & {$[117]$} \\
$\mathrm{Ni} / \mathrm{CeO}_{2}$ & 0.23 & - & 103.4 & {$[118]$} \\
$\mathrm{Ni}-\mathrm{ZrO}{ }_{2} / \mathrm{CeO}_{2}$ & 0.3 & - & 43.4 & {$[119]$} \\
$\mathrm{NiO}-\mathrm{MgO}_{2} / \mathrm{Al}_{2} \mathrm{O}_{3}$ & 0.895 & - & 731.6 & {$[120]$} \\
$\mathrm{NiO}-\mathrm{MgO} / \mathrm{Al}_{2} \mathrm{O}_{3}$ & 0.936 & - & 34.6 & {$[121]$} \\
$\mathrm{NiO}-\mathrm{MgO} / \mathrm{Al}_{2} \mathrm{O}_{3}$ & 0.977 & - & 37.8 & {$[121]$} \\
\hline
\end{tabular}

Despite that nickel catalysts are more affordable, noble metals such as $\mathrm{Pt}, \mathrm{Ru}$, Ir and $\mathrm{Rh}$, are more effective and operational at cooler temperatures. However, newly developed energy nickel-based catalysts were found with performance comparable to noble metal catalysts. The effort for improving the performance of nickel, aiming to improve it, is nevertheless surmounting the drawbacks of Ni-based catalysts $[13,73,79]$.

Chemical industry applications typically postulate that catalysts should be deposited in structural supports, such as pellets or monoliths, to reduce pressure drops in the reactors [122]. The catalyst supports are usually solids with a large surface area and neutral supports, such as $\mathrm{SiO}_{2}$, show high stability and low carbon deposition. The evaluation of surface area is deemed as essential, insofar that a higher surface area is considered as a good indicator for identifying more active catalysts. 
It is established that the use of different supports in nickel-based catalysts is reflected on very distinct catalytic performances [123,124]. Higher $\mathrm{H}_{2}$ selectivity and activity are achieved with a very stable active phase, implying the establishment of strong interactions between the metal phase and support. The surface area of catalysts and active metals dispersion depend on the interaction between the metal and the support. One study [123] reported that for the supports $\mathrm{MgO}, \mathrm{CeO}_{2}$, and $\mathrm{TiO}_{2}$, at $600{ }^{\circ} \mathrm{C}$, and molar ratio S/G of 9, the order of selectivity for $\mathrm{H}_{2}$ followed the sequence $\mathrm{CeO}_{2}(70 \%)>\mathrm{MgO}(40 \%)>\mathrm{TiO}_{2}(15 \%)$. Indeed, ceria-supported catalysts show low carbon deposition, due to a higher surface area and metal dispersion, due to the formation of a good interaction with active nickel phase. Also $\mathrm{CeO}_{2}$, a compound with oxygen storage-release aptitude, shows high opposition to coke buildup, due to the release of oxygen that afterward reacts with deposited carbon with a reduction of coke. Moreover, $\mathrm{Ni} / \mathrm{CeO}_{2}$ catalysts are also able to increase methane reforming and WGS reaction.

Nickel supported in silicon carbide $(\mathrm{SiC})$ has shown a high stability and high yield of syngas, along the time on stream, with low carbon deposits. The Ni layer, posted on the SiC support, did not form coke nano-filaments, contrarily, e.g., to Ni placed on an alumina carrier. This fact is probably due to distinctive interactions between $\mathrm{Ni}$ and the $\mathrm{SiC}$ surface, leading to the formation of specific exposed nickel surfaces which were not able to develop carbon nanofilaments [125]. Coke, particularly as a nanofilament form, may cause severe inactivation of the catalyst surface and breakdown of the support, which can lead to a pressure drop along the catalyst bed and possible damage to the reactor [126]. Silicon carbide display a whole set of properties, considered good for catalyst support materials, such as high thermal conductivity and mechanical strength, high resistance to oxidation, chemical inertia and low specific weight. $\mathrm{SiC}$ can serve as catalyst support, withstanding drastic reactional environments such as highly endothermic or exothermic reactions or strong acidic or basic solutions [127]. As a neutral material, SiC favors a contribution of nickel to GSR, in dehydrogenation and decarbonylation mechanisms. This material contributes to the minimization of undesirable secondary reactions, occurring under acid and basic conditions. Thereby, a Ni/SiC catalyst could promote high stability to GSR reactions and low-carbon deposit [84]. Another characteristic pointed to $\mathrm{Ni} / \mathrm{SiC}$ catalysts is the formation of gas products with a small ratio $\mathrm{H}_{2} / \mathrm{CO}$, between 1 and 1.9, adequate for Fischer-Tropsch and methanol synthesis [128].

As aforementioned, ceria shows good characteristics for GSR and has been also suggested as a valid promoter $[129,130]$. Indeed, ceria shows an aptitude to stabilize the nickel active phase and to promote the reforming of intermediated hydrocarbons with oxygen, contributing thereby for decreasing the coke deposits. Another suggestion is that ceria, usually on support acid sites, inhibits secondary dehydration reactions that give rise to hydrocarbons which lead to coke formation generating thereby a swift catalyst inactivation [131].

An alternative for improving GSR is the use of hydroxyapatite (HAP) supported Ni-Ce-Cu catalysts [72]. HAP is a biomaterial with excellent stability at high temperatures that can be obtained from bones, teeth and mineral rocks. This material shows a mesoporous structure and particle dimensions ranging between $5 \mathrm{~nm}$ and $40 \mathrm{~nm}$, showing high porosity and high surface area. Also, HAP is a support that upgrades metal dispersion, due to a hexagonal configuration of the apatite structure.

It was found that an increase in copper content in the catalysts led to higher glycerol conversion and hydrogen production. Indeed, from a long time ago that copper-based catalysts are recognized as compounds with aptitude for GSR, being operative at mild temperatures and showing better resistance to poisons during dehydrogenation and WGS [132]. The synergy between $\mathrm{CuO}$ and $\mathrm{Ce}_{2} \mathrm{O}$ on $\mathrm{HAP}$ in the GSR, led to more active sites of catalysts, and the presence of $\mathrm{CeO}_{2}$ eased the reduction of bulk $\mathrm{CuO}$ to $\mathrm{Cu}$, with lower $\mathrm{H}_{2}$ consumption and increase of uniform spread of $\mathrm{Cu}$ species over the catalyst surfaces. In catalysts with higher loading of $\mathrm{CuO}$ and $\mathrm{CeO}_{2}$ the $\mathrm{CuO}-\mathrm{CeO}_{2}$ contact area is maximized, providing a strong synergy amidst these compounds. This synergy led to a high dispersion of the copper oxide on $\mathrm{CeO}_{2}$ and to the upgrading of the chemical activity of $\mathrm{Cu}$. The overall proceeding of GSR with Ni-based catalysts can be quantified through the Langmuir-Hinshelwood 
model which follows a molecular adsorption, on catalytic basic and acid catalytic sites, of both glycerol and steam. Therein the adsorbed glycerol reacts with the adsorbed hydrogen to afford simpler molecules to produce hydrogen and carbon dioxide. The surface reactions control the rate of the whole process $[13,73,116]$.

A experimental study [72] showed that a catalyst with (\% mass) $3 \% \mathrm{Ni}, 7.5 \%$ of $\mathrm{Ce}$, and $7.5 \%$ of $\mathrm{Cu}$ relatively to HAP mass, at atmospheric pressure, $600{ }^{\circ} \mathrm{C}$, and $\mathrm{S} / \mathrm{G}$ ratio of 8 , allowed achieving a glycerol conversion of $97.3 \%$ and a hydrogen yield of $57.5 \%$, which were better results than these correponding to a set of three other prepared $\mathrm{Ni}-\mathrm{Ce}-\mathrm{Nu}, \mathrm{HAP}$ supported catalysts. The catalysts with higher $\mathrm{Cu}$ and $\mathrm{Ce}$ loadings may maximize the $\mathrm{CuO}-\mathrm{CeO}_{2}$ contact area, providing a stronger interaction between these species and augment the surface area of the catalysis agent. The catalyst with lower Cu mass ( $3 \%$ mass), displayed the lower surface area and hydrogen production compared to other three catalysts doped with $7.5 \%$ of $\mathrm{Cu}$. This may have resulted in all the copper cations substituting the position of HAP cations $\left(\mathrm{Ca}^{2+}\right)$ so that $\mathrm{CeO}_{2}$ not thoroughly interacted with $\mathrm{CuO}$ to lead to the crystalline $\mathrm{CeO}_{2}$, which would have same control on the specific surface area of the catalysis agents $[133,134]$. A Ni-based catalyst with $8.4 \mathrm{wt} \% \mathrm{Ni} / \gamma-\mathrm{Al}_{2} \mathrm{O}_{3} / 6 \mathrm{wt} \% \mathrm{La}_{2} \mathrm{O}_{3}$ at $500{ }^{\circ} \mathrm{C}$ and $4 \mathrm{~atm}$, allowed obtaining a 100\% glycerol with $99.7 \% \mathrm{H}_{2}$ yield conversion, after $8 \mathrm{~h}$ [135].

The use of low quantities of noble metals, such as $\mathrm{Pt}, \mathrm{Ru}, \mathrm{Pd}$ and $\mathrm{Ir}$, is proved to increase the efficiency of $\mathrm{Ni} / \mathrm{CeO}_{2}-\mathrm{Al}_{2} \mathrm{O}_{3}$ leading to greater $\mathrm{H}_{2}$ production, compared with original catalysis agents [136]. The best GSR reaction occurred with the addition of $\mathrm{Pt}$ at $700{ }^{\circ} \mathrm{C}$. The addition of $\mathrm{Pt}$, during the GSR stabilized the Ni sites in the reduced state, with higher production of hydrogen and a lower deposition of coke. An electronic synergy between Ni and noble metal particles, may justify the positive results influence on the catalysis of GSR. Also, there is an additional aptitude of noble metals to catalyze the breakage of $C-C$ chemical bonds. The coke deposition was of about $30 \%$ lower in the case of $\mathrm{Ni} / \mathrm{Pt}$ catalyst, compared with the $\mathrm{Ni}$ catalyst. Ni/Pt catalyst also provided a higher hydrogen increase $(45 \%)$ in hydrogen production over the Ni catalyst. The promoting effect of small amounts of noble metals included a diminishing in the reduction temperatures of $\mathrm{NiO}$ species intereacting with the support, due to the hydrogen spillover effect. The hydrogen spillover leads to a reduction of $\mathrm{Ni}$ in the NiPt, NiIr and NiPd catalysts. This effect is a motion of atomic hydrogen through the catalyst surface, reducing thereby $\mathrm{Ni}$ more readily comparatively to the gaseous $\mathrm{H}_{2}$. The $\mathrm{CeO}_{2}$, molecules also included in the support, are also submitted to hydrogen spillover with a consequent easier reduction at smaller temperatures [136].

$\mathrm{Pt}$ is usually more active and stable in glycerol steam reforming and at lower reaction temperatures, at about $400{ }^{\circ} \mathrm{C}[137,138]$. Platinum on carbon $(\mathrm{Pt} / \mathrm{C})$, a form of platinum used as a catalyst wherein the metal is supported on activated carbon to maximize its surface area and activity, induces lower carbon formation on GSR. This is reflected on a tiny fraction of formed $\mathrm{C}_{2}$ compounds which is indicative of lower carbon generation on the $\mathrm{Pt} / \mathrm{C}$ catalyst and on a higher stability on the reforming, than other Pt-based materials on different supports, e.g., $\mathrm{Al}_{2} \mathrm{O}_{3} ; \mathrm{ZrO}_{2} ; \mathrm{MgO} / \mathrm{ZrO}_{2}$ and $\mathrm{CeO}_{2} / \mathrm{ZrO}_{2}$ [139]. Nevertheless, although $\mathrm{Pt} / \mathrm{C}$ supported catalysts show efficiency on glycerol reforming at cool temperatures, they are considered as more apt for syngas production. Oxide supports, by promoting the WGS reaction, are considered as more appropriate for $\mathrm{H}_{2}$ production, with minor $\mathrm{CO}$ amounts [73,139]. Sad et al. [67], comparing Pt-based catalysts with supports of $\mathrm{SiO}_{2}, \mathrm{MgO}$, $\mathrm{Al}_{2} \mathrm{O}_{3}$, and $\mathrm{TiO}_{2}$, found better results using a $\mathrm{SiO}_{2}$ support with a chloride-free aqueous solution (tetramine platinum nitrate, $\left.\mathrm{Pt}\left(\mathrm{NH}_{3}\right)_{4}\left(\mathrm{NO}_{3}\right)_{2}\right)$. This catalyst, at $350{ }^{\circ} \mathrm{C}$, provided conversions of $100 \%$ from glycerol to gaseous products, with a $79 \%$ yield of hydrogen. In the study of Sad et al. [67], $\mathrm{SiO}_{2}$ support was chosen due to its lower acidity in comparison with other supports such as $\mathrm{Al}_{2} \mathrm{O}_{3}$ or $\mathrm{ZrO}_{2}$. A $100 \%$ hydrogen yield was obtained using a double-bed catalysis system $(0.5 \mathrm{wt} \%$. $\mathrm{Pt} / \mathrm{SiO}_{2}+0.5 \mathrm{wt} \%$. $\mathrm{Pt} / \mathrm{TiO}_{2}$ ). This scheme included the best catalyst for improving the yield of the two significant GSR reactions which are glycerol decomposition and WGS reaction, [67].

It was established by lab experimentation than $\mathrm{Ni} / \mathrm{SiO}_{2}$ and $\mathrm{Pt} / \mathrm{SiO}_{2}$ catalysts followed the same reaction steps, involving dehydrogenation on GSR [140]. The latter catalyst shows higher 
stability, metal dispersion, higher activity for gaseous products, and higher selectivity to $\mathrm{H}_{2}$ [138]. The space-time used in the study of Pompeo et al. [138], ranged from 0.44 to $1.66 \mathrm{~min}$, with catalyst mass variation. A total conversion to gaseous products was achieved in lab reforming conditions with changes in temperature and space-time variables. The study of Pompeo et al. [138], with a nickel-based catalyst under $450{ }^{\circ} \mathrm{C}$ and after 1.66 min achieved a total glycerol conversion of $100 \%$, being $80 \%$ regarding to gas conversion while the remaining $20 \%$ refers to the liquid fraction. A molar yield of hydrogen of $70 \%$ was reached under such condition. Also, in the same study, a unique change of $\tau$ to 0.88 provided changes only in gas conversion to $78 \%$ and hydrogen yield of $66 \%$, respectively. A platinum/yttrium oxide $\left(\mathrm{Pt} / \mathrm{Y}_{2} \mathrm{O}_{3}\right)$ catalyst was tested for GSR leading, at $600{ }^{\circ} \mathrm{C}$, to a significant glycerol conversion of $95 \%$ and a hydrogen yield of $90 \%$ [141].

The addition of ceria to platinum catalysts, on an alumina basis, lowers its acidic content, upgrading thereby the catalyst stability and $\mathrm{H}_{2}$ selectivity, and lessening the formation of impurities and coke deposition $[139,142]$. Also, it was shown that the energy requirement for CO adsorption on Pt-based catalysts was reduced by the application of metal alloys [143]. For example, bimetallic platinum-rhenium/C catalyst agents with $\mathrm{Pt} / \mathrm{Re}$ atomic ratios lower than 1 yield through GSR a fivefold increase in syngas yield, comparatively with monometallic $\mathrm{Pt} / \mathrm{C}$ and $\mathrm{Pt}$-Re with a Pt/Re molar ratio higher than 10. A main effect should be the attenuation of the chemical bond between $\mathrm{CO}$ and surface, facilitating the regeneration of the catalytic sites [144].

Ruthenium, along with nickel and platinum, is the least expensive of the noble metals and a promising material for the catalysis of hydrogen production through GSR [73]. Indeed, by comparing the glycerol steam reforming activity of catalysts supported oxides, Ru was shown as the best along seven elements of Groups VIII and X. $\mathrm{Y}_{2} \mathrm{O}_{3}$ was revealed as the better support for Ru based catalysts with an $100 \%$ conversion of glycerol and an $85 \%$ hydrogen yield, for a $3 \%$ catalyst weight loading at $600{ }^{\circ} \mathrm{C}$ and $101.3 \mathrm{kPa}$ [145]. This was attributed to the yttrium aptitude for promoting the water gas shift reaction. A $3 \mathrm{wt} \% \mathrm{Ru} / \mathrm{Y}_{2} \mathrm{O}_{3}$ material was also found as much resistant to inactivation caused by carbon deposition $[145,146]$.

\subsubsection{Alternative GSR Reactor Configurations}

The configuration of reactors has a paramount relevance for circumventing the thermodynamic constraints of glycerol steam reforming [84]. The membrane reactor (MR) is an alternative technology to the conventional system for production of hydrogen, by a green process under the global concept of Process Intensification Strategy, wherein a unique operation unit performs both the chemical reactions as the hydrogen separation/purification process [13,73]. The International Union of Pure and Applied Chemistry (IUPAC), defined MR as an apparatus able to perform a reaction along a membrane separation in the same physical boundary. The membrane reactor technology has been widely used in $\mathrm{H}_{2}$ production through reforming reactions of hydrocarbons and alcohols. The membrane, in the equilibrium restricted reaction, allows overcoming the thermodynamic equilibrium, due to a selective removal of hydrogen which is a reaction product, shifting the reaction to a higher products formation and thereby increasing the conversion rate. The advantages of membrane reactors are the same of sorption enhanced, with to the difference of $\mathrm{CO}_{2}$ emissions. The MR with only one reactor, are considered thereby as more compact, more cost-effective and with lower investment costs [147].

$\mathrm{H}_{2}$-selective membranes may be dense metallic ( $\mathrm{Pd}$ and $\mathrm{Pd}$ alloys) with pore size $<0.5 \mathrm{~nm}$, proton conducing dense ceramic membranes (perovskites with a general formula $\mathrm{LaCo}_{0.99} \mathrm{X}_{0.01} \mathrm{O}_{3}$ with $\mathrm{X}=\mathrm{Au}, \mathrm{Ag}, \mathrm{Cu}$ and $\mathrm{Pt}$ ), dense polymeric membranes (e.g., polyimides or cellulose) or micro-, meso-, or macroporous membranes with pore sizes varying between $2 \mathrm{~nm}$ and $50 \mathrm{~nm}[148,149]$. In the last years, an intensive effort has been made to develop composite membranes for GSR, consisting of thin metal films placed over porous supports. The dense metallic membranes are better for obtaining a high purified $\mathrm{H}_{2}$ product, because they can endure high temperatures and are very selective towards hydrogen. Pd-derived metals are nowadays considered as most promising materials for membranes, especially Pd alloys, such as Pd-Ag and Pd-Cu, which are more resistant to poisoning and brittleness, 
due respectively to contact with $\mathrm{CO}$ or $\mathrm{H}_{2} \mathrm{~S}$, in crude glycerol, and with $\mathrm{H}_{2}$ at temperatures below $300{ }^{\circ} \mathrm{C}$ and pressures below $2 \mathrm{MPa}$ [150-152]. Some of these types of membranes and their specifications are summarized on Table 2.

Table 2. Specifications of membranes already disclosed in published studies (adapted from Silva et al. [73]).

\begin{tabular}{|c|c|c|c|c|c|c|c|}
\hline Membrane & $\mathrm{T}\left({ }^{\circ} \mathrm{C}\right)^{\mathrm{a}}$ & $\Delta \mathrm{P}(\mathrm{kPa})^{\mathrm{b}}$ & $\delta(\mu \mathrm{m})$ & $\begin{array}{c}\text { Permeance to } \mathrm{H}_{2} \\
\left(\mathrm{~mol} \mathrm{~m}^{-2} \cdot \mathrm{s}^{-1} \cdot \mathrm{Pa}^{-0.5}\right)\end{array}$ & $\begin{array}{l}\text { Ideal Selectivity } \\
\qquad \mathrm{H}_{2} / \mathrm{N}_{2}\end{array}$ & $\begin{array}{c}E_{a, \mathrm{Pd}} \\
\left(\mathrm{kJmol}^{-1}\right)\end{array}$ & Refs. \\
\hline Pd-25 wt \% Ag & 300 & $10-150$ & 50 & $1.15 \times 10^{-4 c}$ & $\infty$ & 10.72 & [153] \\
\hline Pd-23-25 wt \% Ag & 350 & 700 & 84 & $2.26 \times 10^{-4 c}$ & $\infty$ & 2.92 & [154] \\
\hline $\mathrm{Pd}_{46.6}-\mathrm{Cu}_{53.4}$ & 400 & 345 & 40 & $4.50 \times 10^{-4 \mathrm{c}}$ & - & 5.80 & [155] \\
\hline $\mathrm{Pd}_{45.8}-\mathrm{Cu}_{51.9}-\mathrm{Ag}_{2.3}$ & 400 & 345 & 40 & $3.50 \times 10^{-4 c}$ & - & 10.20 & [155] \\
\hline $\mathrm{Pd}-5$ wt $\% \mathrm{Pt} / \mathrm{YSZ}$ & 400 & $57.9-609.5$ & 6.6 & $1.18 \times 10^{-3 c}$ & 994 & - & [156] \\
\hline $\mathrm{Pd} / \mathrm{Ag} / \mathrm{PSS}$ & 400 & 100 & 4.0 & $1.71 \times 10^{-3 c}$ & 1000 & 11.90 & [157] \\
\hline Pd/Pencil/PSS & 450 & 100 & 7.0 & $1.40 \times 10^{-3 c}$ & 120 & 13.80 & [158] \\
\hline $\mathrm{Pd} / \mathrm{TiO}_{2} / \mathrm{Ti}-\mathrm{Al}$ & 500 & $588-704^{c}$ & 14.0 & $1.07 \times 10^{-3 c}$ & $\infty$ & 13.65 & [159] \\
\hline $\mathrm{Pd}_{78} \mathrm{Ag}_{9} \mathrm{Au}_{13}$ & 450 & - & 14.0 & $1.16 \times 10^{-3 c}$ & - & - & [160] \\
\hline $\mathrm{Ti}_{50.864} \mathrm{Ni}_{46.961} \mathrm{Pd}_{4.175}$ & 450 & 100 & 45.0 & $3.84 \times 10^{-6 c}$ & - & 42.23 & [161] \\
\hline $\mathrm{Pd}_{95} \mathrm{Au}_{5}$ & 400 & - & 2.5 & $4.40 \times 10^{-3 c}$ & $\geq 10,000$ & - & [162] \\
\hline $\mathrm{Pd}_{95} \mathrm{Y}_{5}$ & 400 & - & 2.0 & $5.50 \times 10^{-3 c}$ & $\geq 10,000$ & - & [162] \\
\hline $\mathrm{Pd}_{73} \mathrm{Cu}_{26} \mathrm{Y}_{1}$ & 400 & - & 2.0 & $2.50 \times 10^{-3 c}$ & $\geq 10,000$ & - & [162] \\
\hline
\end{tabular}

YSZ: Yttria-stabilized zirconia; PSS: Porous stainless steel; ${ }^{a}$ Temperature at which the permeance was obtained;

${ }^{b}$ Trans-membrane pressure difference at which the permeance was obtained; ${ }^{c}$ Calculated values. $\infty$-infinite selectivity for hydrogen.

In porous membranes, the process is controlled by competing for transport mechanisms based on Poiseuille or Knudsen diffusion principles applied in situations where the average pore diameter is much wider than the mean free path of molecules or the pore diameter are comparable or smaller than the mean free path, respectively.

For dense membranes the transport mechanism is represented by solution-diffusion, which theoretically is controlled by three main types of fluxes, depicted by the following equations:

$$
\begin{gathered}
J_{1}=k_{1} p_{\mathrm{H}_{2,1}}-k_{2} \bar{p}^{2}{ }_{\mathrm{H}_{2,1}} \\
J_{2}=k_{2} \bar{p}^{2}{ }_{\mathrm{H}_{2,1}}-k_{1} p_{\mathrm{H}_{2,2}} \\
J_{3}=D\left(C_{2}-C_{1}\right)
\end{gathered}
$$

The first equation represents $\mathrm{H}_{2}$ adsorption on the membrane side at higher partial pressure of hydrogen. The second equation represents the dissociation into atomic $\mathrm{H}_{2}$ combined with a reversible dissociative into atomic $\mathrm{H}_{2}$, and third equation represents the final desorption of recombined $\mathrm{H}_{2}$ molecules. After some calculations the flux of $\mathrm{H}_{2}$ that permeated through the membrane can be expressed as:

$$
J_{\mathrm{H}_{2}}=\mathrm{P}_{\mathrm{e}, \mathrm{H}_{2}} / \delta\left(p_{\mathrm{H}_{2, \text { ret }}}^{n}-p_{\mathrm{H}_{2, \text { permeate }}}^{n}\right)
$$

where $\mathrm{P}_{\mathrm{e}, \mathrm{H}_{2}}$ is the $\mathrm{H}_{2}$ permeability through the membrane, and $p_{\mathrm{H}_{2, \text { ret }}}$ and $p_{\mathrm{H}_{2, \text { permeate }}}$ are the hydrogen partial pressure in the retentate and permeate sites and $\mathrm{n}$ the exponent expressing the dependence of $\mathrm{H}_{2 f l u x}$ to the $\mathrm{H}_{2}$ partial pressure and $\delta$ the thickness of the palladium layer. The ratio $\mathrm{P}_{\mathrm{e}, \mathrm{H}_{2} / \delta}$ is the so-called permeance or pressure-normalized flux, and the exponent $\mathrm{n}$ takes values in the range 0.5 and 1 . The value 0.5 is attributed when the diffusion of the atomic hydrogen through the metal lattice is the limiting step (Sieverst-Fick law). The value 1 corresponds to situation wherein the surface adsorption is rate limiting. The temperature influence on the $\mathrm{H}_{2}$ permeability can be described as an Arrhenius type relationship:

$$
P_{\mathrm{Pd}, \mathrm{H}_{2}}=P_{\mathrm{Pd}, \mathrm{H}_{2}}^{0} \exp \left(-E_{a \mathrm{Pd}} / R T\right)
$$

where $P_{\mathrm{Pd}, \mathrm{H}_{2}}^{0}$ is the pre-exponential factor and $E_{a \mathrm{Pd}}$ the activation energy of the membrane. 
The GSR is an endothermic and equilibrium limited process which requires high operating temperatures. The GSR process involves decomposition of glycerol, followed by the water gas shift reaction multiplied by a factor of 3 . The existence of side reactions leads to a decrease in hydrogen production which is almost surely smaller than the theoretical yield of 7 moles of hydrogen per mole of consumed glycerol [13]. Theoretical studies on new reactor configurations that combine GSR with carbon dioxide or hydrogen-selective removal have allowed obtaining higher hydrogen production and decrease the production of methane and carbon monoxide by-products by shifting the thermodynamic equilibrium $[92,109]$. Such processes allow obtaining higher energetic yield than a traditional reactor, while operating at milder operating conditions. An additional option is the simultaneous removal of $\mathrm{CO}_{2}$ and $\mathrm{H}_{2}$ through a device which is the so-called sorption enhanced membrane reactor (SEMR), wherein the GSR would be performed concomitantly with the removal of carbon dioxide and hydrogen from the reaction zone, through a specific sorbent and a selective membrane, respectively. A thermodynamic analysis through minimization of Gibbs free energy was carried out by Silva et al. [84], for evaluating the dynamics of the several alternatives for GSR reactors (MR, SER, TR, and SEMR) concerning the equilibrium concentrations and yields of chemical reagents and products. Such device for SEMR would require a configuration with two parallel reactors, one for producing $\mathrm{H}_{2}$ trough GSR, sorting out by the flue gas in a pure state due to the membrane selective permeation, and the other for regeneration through the removal of $\mathrm{CO}_{2}$ from the outlet gas. Each reactor has two operation modes through successive reaction-regeneration cycles. At same crucial moment, the sorbent is saturated, with the removal of $\mathrm{CO}_{2}$ and the gas flowing to the outlet. At this moment the valve system moves to an inert gas feeding only such as $\mathrm{N}_{2}$ to promote regeneration of the sorbent bed, so that the latter can retain $\mathrm{CO}_{2}$ again. During this step, the other reactor is under a reaction stage wherein $\mathrm{H}_{2}$ is produced. The $\mathrm{CO}_{2}$ and $\mathrm{CO}$ can affect membrane permeability to hydrogen, but this effect is reversible. The operating conditions, should be adequate for the catalysis, particularly in terms of factors such as temperature, pressure or $\mathrm{S} / \mathrm{G}$ ratio, sorbent and membrane selectivity for $\mathrm{H}_{2}$. Numerical sensitivity analysis on thermodynamic variables can be relevant for providing information about the technical feasibility and optimizing of the performance of this system. Available results, obtained from this kind of analysis, showed that temperatures of about $520^{\circ} \mathrm{C}$, steam-glycerol ratio of 9 , atmospheric pressure, carbon dioxide fraction removal of 0.99 and hydrogen fraction removal of 0.8 , allowed obtaining the maximum possible yield for hydrogen of 7 . The production of $\mathrm{CO}$ and $\mathrm{CH}_{4}$ was not significant under these conditions. The hydrogen production was higher with SEMR than with sorption enhanced reactor (SER) or membrane reactor (MR) and much higher than with traditional reactor (TR), but the difference was much attenuated with the increase of temperature of $227-527{ }^{\circ} \mathrm{C}$. The results showed an increase in molar hydrogen yield of about $217 \%, 47 \%$ and $22 \%$ of SEMR comparatively to MR, SER, and TR, respectively. MR molar hydrogen was also about $160 \%$ higher than TR molar hydrogen yield.

\section{Conclusions}

With this review, we intended to evaluate three major approaches for crude glycerol, obtained from production of biodiesel, through purification and conversion into added-value products which were glycerol carbonates, acetins, and hydrogen. By doing so, the processes were described and discussed in terms of their advantages. The manuscript was prepared to focus on a technological point of view, in particular emphasizing the catalysis and experimental analysis. Regarding glycerol steam reforming a thermodynamic discussion is also shown, by comparing several experimental apparatuses. The research work reviewed and disclosed herein demonstrates that glycerol can be, in fact, a source for manufacturing energy carriers and chemicals in the future. These by-products can, thereby, contribute to a sustainable environmental circular economy turning the biodiesel industry into a profitable one.

Acknowledgments: Fundação para Ciência e a Tecnologia is acknowledged for supporting CERENA strategic project (FCT-UID/ECI/04028/2013) and R. Galhano dos Santos (Postdoctoral Grant SFRH/BPD/105662/2015). 
Author Contributions: All authors contributed equally to the paper towards the bibliographic search, reading, writing it.

Conflicts of Interest: The authors declare no conflict of interest.

\section{References}

1. Demirbas, A. Biofuels from agricultural biomass. Energy Sources Part A Recovery Util. Environ. Eff. 2009, 31, 1573-1582. [CrossRef]

2. Gírio, F.; Marques, S.; Pinto, F.; Oliveira, A.C.; Costa, P.; Reis, A.; Moura, P. Biorefineries in the World. In Biorefineries, Targeting Energy, High Value Products, An Waste Valorization; Rabaçal, M., Ferreira, A., Silva, C., Costa, M., Eds.; Springer: Berlin, Germany, 2017; pp. 227-281.

3. Beaudoin, F.; Sayanova, O.; Haslam, R.P.; Bancroft, I.; Napier, J.A. Oleaginous crops as integrated production platforms for food, feed, fuel and renewable industrial feedstock. OCL 2014, 21, D606. [CrossRef]

4. Demirbas, A. Fuels from Biomass. In Biohydrogen—For Future Engine Fuel Demands; Springer: Berlin, Germany, 2009; pp. 43-59, ISBN 978-1-84882-511-6.

5. Bülow, L.; Stymne, S. Plastics direct from the field? In Bioenergy—For What and How Much? Johansson, B., Ed.; Swedish Research Coucil for Environment Agricultural Sciences and Space Planning: Stockholm, Sweden, 2008; ISBN 978-91-540-6006-1.

6. Misra, M.; Misra, A.N. Jatropha: The biodiesel plant biology, tissue culture and genetic transformationA review. Int. J. Pure Appl. Sci. Technol. 2010, 1, 11-24.

7. Hayder, M.; Rakotondramanga, S.; Palmberg-Lerche, C. Oil Trees for Energy in the Near East Region; Palmberg-Lerche, C., Ed.; FAO: Cairo, Egypt, 2012; ISBN 978-92-5-107120-5.

8. De Rossi, A.; Vescio, R.; Russo, D.; Macrì, G. Potential Use of Jatropha curcas L. on Marginal Lands of Southern Italy. Procedia Soc. Behav. Sci. 2016, 223, 770-775. [CrossRef]

9. Yin, F.; Liu, L.; Jiang, D.; Ren, H. Assessments of suitability, energy capacity and environment impact on biodiesel from Jatropha curcas L. Nongye Gongcheng Xuebao/Trans. Chin. Soc. Agric. Eng. 2012, 28, 201-208.

10. Xie, X.; Zhang, T.; Wang, L.; Huang, Z. Regional water footprints of potential biofuel production in China. Biotechnol. Biofuels 2017, 10, 95. [CrossRef] [PubMed]

11. Kant, P.; Wu, S. The extraordinary collapse of jatropha as a global biofuel. Environ. Sci. Technol. 2011, 45, 7114-7115. [CrossRef] [PubMed]

12. Sheehan, J.; Camobreco, V.; Duffield, J.; Shapouri, H.; Graboski, M.; Tyson, K.S. An Overview of Biodiesel and Petroleum Diesel Life Cycles; National Renewable Energy Laboratory: Golden, CO, USA, 2000.

13. Bagnato, G.; Iulianelli, A.; Sanna, A.; Basile, A. Glycerol production and transformation: A critical review with particular emphasis on glycerol reforming reaction for producing hydrogen in conventional and membrane reactors. Membranes 2017, 7, 17. [CrossRef] [PubMed]

14. Okoye, P.U.; Hameed, B.H. Review on recent progress in catalytic carboxylation and acetylation of glycerol as a byproduct of biodiesel production. Renew. Sustain. Energy Rev. 2016, 53, 558-574. [CrossRef]

15. Vivek, N.; Sindhu, R.; Madhavan, A.; Anju, A.J.; Castro, E.; Faraco, V.; Pandey, A.; Binod, P. Recent advances in the production of value added chemicals and lipids utilizing biodiesel industry generated crude glycerol as a substrate-Metabolic aspects, challenges and possibilities: An overview. Bioresour. Technol. 2017, 239, 507-517. [CrossRef] [PubMed]

16. Ciriminna, R.; Pina, C.; Della; Rossi, M.; Pagliaro, M. Understanding the glycerol market. Eur. J. Lipid Sci. Technol. 2014, 116, 1432-1439. [CrossRef]

17. Cortez, L.; Lora, E.; Gómez, E. Biomassa Para Energia; Editora da Unicamp: Campinas, Brazil, 2008.

18. Tan, H.W.; Abdul Aziz, A.R.; Aroua, M.K. Glycerol production and its applications as a raw material: A review. Renew. Sustain. Energy Rev. 2013, 27, 118-127. [CrossRef]

19. Jensen, K.; Menard, J.; English, B.C. U.S. and Tennessee Biodiesel Production-2007 Industry Update; The University of Tennessee: Knoxville, TN, USA, 2007.

20. He, Q.; McNutt, J.; Yang, J. Utilization of the residual glycerol from biodiesel production for renewable energy generation. Renew. Sustain. Energy Rev. 2017, 71, 63-76. [CrossRef]

21. Claude, S. Research of New Outlets For Glycerol-Recent Developments in France. Lipid Sci. Technol. 1999, 101, 101-104. [CrossRef] 
22. Hejna, A.; Kosmela, P.; Formela, K.; Piszczyk, Ł.; Haponiuk, J.T. Potential applications of crude glycerol in polymer technology-Current state and perspectives. Renew. Sustain. Energy Rev. 2016, 66, 449-475. [CrossRef]

23. Epp, T. Combustion of Glycerine for Combined Heat And Power Systems in Biodiesel Processing Facilities. Bachelor's Thesis, University of Manitoba, Winnipeg, MB, Canada, 2008.

24. Hiremath, A.; Kannabiran, M.; Rangaswamy, V. 1,3-Propanediol production from crude glycerol from jatropha biodiesel process. New Biotechnol. 2011, 28, 19-23. [CrossRef] [PubMed]

25. Wijesekara, R.G.S.; Nomura, N.; Sato, S.; Matsumura, M. Pre-treatment and utilization of raw glycerol from sunflower oil biodiesel for growth and 1,3-propanediol production byClostridium butyricum. J. Chem. Technol. Biotechnol. 2008, 83, 1072-1080. [CrossRef]

26. Ardi, M.S.; Aroua, M.K.; Hashim, N.A. Progress, prospect and challenges in glycerol purification process: A review. Renew. Sustain. Energy Rev. 2015, 42, 1164-1173. [CrossRef]

27. Kongjao, S.; Damronglerd, S.; Hunsom, M. Purification of crude glycerol derived from waste used-oil methyl ester plant. Korean J. Chem. Eng. 2010, 27, 944-949. [CrossRef]

28. Hájek, M.; Skopal, F. Treatment of glycerol phase formed by biodiesel production. Bioresour. Technol. 2010, 101, 3242-3245. [CrossRef] [PubMed]

29. Javani, A.; Hasheminejad, M.; Tahvildari, K.; Tabatabaei, M. High quality potassium phosphate production through step-by-step glycerol purification: A strategy to economize biodiesel production. Bioresour. Technol. 2012, 104, 788-790. [CrossRef] [PubMed]

30. Van Gerpen, J.; Shanks, B.; Pruszko, R.; Clements, D.; Knothe, G. Biodiesel Production Technology; National Renewable Energy Laboratory: Golden, CO, USA, 2004.

31. Noble, R.D.; Terry, P.A. Principles of Chemical Separations with Environmental Applications; Cambridge University Press: Cambridge, UK, 2004; ISBN 9780511616594.

32. Maleta, V.N.; Kiss, A.A.; Taran, V.M.; Maleta, B.V. Understanding process intensification in cyclic distillation systems. Chem. Eng. Process. Process Intensif. 2011, 50, 655-664. [CrossRef]

33. Maleta, B.V.; Shevchenko, A.; Bedryk, O.; Kiss, A.A. Pilot-scale studies of process intensification by cyclic distillation. AIChE J. 2015, 61, 2581-2591. [CrossRef]

34. Kiss, A.A.; Ignat, R.M. Enhanced methanol recovery and glycerol separation in biodiesel production-DWC makes it happen. Appl. Energy 2012, 99, 146-153. [CrossRef]

35. Petlyuk, F.B.; Platonov, V.M.; Slavinskii, D.M. Thermodynamically optimal method for separating multicomponent mixtures. Int. Chem. Eng. 1965, 5, 555-561.

36. Yildirim, Ö.; Kiss, A.A.; Kenig, E.Y. Dividing wall columns in chemical process industry: A review on current activities. Sep. Purif. Technol. 2011, 80, 403-417. [CrossRef]

37. Woinaroschy, A.; Isopescu, R. Divided wall distillation column: Dynamic modeling and control. Comput. Aided Chem. Eng. 2008, 25, 313-318. [CrossRef]

38. Rezkallah, A. Method for Purification of Glycerol. EP2,159,212 A1, 3 March 2010.

39. Isahak, W.N.R.W.; Ismail, M.; Yarmo, M.A.; Jahim, J.M.; Salimon, J. Purification of Crude Glycerol from Transesterification RBD Palm Oil over Homogeneous and Heterogeneous Catalysts for the Biolubricant Preparation. J. Appl. Sci. 2010, 10, 2590-2595. [CrossRef]

40. Manosak, R.; Limpattayanate, S.; Hunsom, M. Sequential-refining of crude glycerol derived from waste used-oil methyl ester plant via a combined process of chemical and adsorption. Fuel Process. Technol. 2011, 92, 92-99. [CrossRef]

41. Hunsom, M.; Autthanit, C. Adsorptive purification of crude glycerol by sewage sludge-derived activated carbon prepared by chemical activation with $\mathrm{H}_{3} \mathrm{PO}_{4}, \mathrm{~K}_{2} \mathrm{CO}_{3}$ and $\mathrm{KOH}$. Chem. Eng. J. 2013, 229, 334-343. [CrossRef]

42. Muralidhara, H.S.; Ko, M.K. Process for the Purification of Crude Glycerol Compositions. WO2,008,156,612 A1, 24 December 2008.

43. Jeromin, L.; Johannisbauer, W.; Blum, S.; Sedelies, R.; Moormann, H.; Holfoth, B.; Plachenka, J. Process for the Purification of Glycerol Water. U.S. Patent 5,527,974 A, 18 June 1996.

44. Indok Nurul Hasyimah, M.A.; Mohammad, A.W.; Markom, M. Influence of Triglycerides on Fouling of Glycerol-Water with Ultrafiltration Membranes. Ind. Eng. Chem. Res. 2011, 50, 7520-7526. [CrossRef] 
45. Onsekizoglu, P. Membrane Distillation: Principle, Advances, Limitations and Future Prospects in Food Industry. In Distillation-Advances from Modeling to Applications; Trakya University Department of Food Engineering: Edirne Turkey, 2012; pp. 233-266. [CrossRef]

46. Wang, K.Y.; Teoh, M.M.; Nugroho, A.; Chung, T.S. Integrated forward osmosis-membrane distillation (FO-MD) hybrid system for the concentration of protein solutions. Chem. Eng. Sci. 2011, 66, 2421-2430. [CrossRef]

47. Kong, P.S.; Aroua, M.K.; Daud, W.M.A.W. Conversion of crude and pure glycerol into derivatives: A feasibility evaluation. Renew. Sustain. Energy Rev. 2016, 63, 533-555. [CrossRef]

48. Ochoa-Gómez, J.R.; Gómez-Jiménez-Aberasturi, O.; Maestro-Madurga, B.; Pesquera-Rodríguez, A.; Ramírez-López, C.; Lorenzo-Ibarreta, L.; Torrecilla-Soria, J.; Villarán-Velasco, M.C. Synthesis of glycerol carbonate from glycerol and dimethyl carbonate by transesterification: Catalyst screening and reaction optimization. Appl. Catal. A Gen. 2009, 366, 315-324. [CrossRef]

49. Chiappe, C.; Rajamani, S. Synthesis of glycerol carbonate from glycerol and dimethyl carbonate in basic ionic liquids. Pure Appl. Chem. 2011, 84, 755-762. [CrossRef]

50. Kouzu, M.; Kasuno, T.; Tajika, M.; Sugimoto, Y.; Yamanaka, S.; Hidaka, J. Calcium oxide as a solid base catalyst for transesterification of soybean oil and its application to biodiesel production. Fuel 2008, 87, 2798-2806. [CrossRef]

51. Gonçalves, V.L.C.; Pinto, B.P.; Silva, J.C.; Mota, C.J.A. Acetylation of glycerol catalyzed by different solid acids. Catal. Today 2008, 133-135, 673-677. [CrossRef]

52. Dosuna-Rodríguez, I.; Gaigneaux, E.M. Glycerol acetylation catalysed by ion exchange resins. Catal. Today 2012, 195, 14-21. [CrossRef]

53. Gao, X.; Zhu, S.; Li, Y. Graphene oxide as a facile solid acid catalyst for the production of bioadditives from glycerol esterification. Catal. Commun. 2015, 62, 48-51. [CrossRef]

54. Liao, X.; Zhu, Y.; Wang, S.G.; Li, Y. Producing triacetylglycerol with glycerol by two steps: Esterification and acetylation. Fuel Process. Technol. 2009, 90, 988-993. [CrossRef]

55. Zhou, L.; Nguyen, T.H.; Adesina, A.A. The acetylation of glycerol over amberlyst-15: Kinetic and product distribution. Fuel Process. Technol. 2012, 104, 310-318. [CrossRef]

56. Chakrabarti, A.; Sharma, M.M. Cationic ion exchange resins as catalyst. React. Polym. 1993, 20, 1-45. [CrossRef]

57. Barbara, P.; Liguori, F. Ion exchange resins: Catalyst recovery and recycle. Chem. Rev. 2009, 109, 515-529. [CrossRef] [PubMed]

58. Dijs, I.J.; Van Ochten, H.L.F.; Van Der Heijden, A.J.M.; Geus, J.W.; Jenneskens, L.W. Erratum: The catalytic performance of sulphonated cross-linked polystyrene beads in the formation of isobornyl acetate. Appl. Catal. A Gen. 2003, 241, 185-203. [CrossRef]

59. Saha, B.; Streat, M. Cation exchange resin-catalysed esterification of acetic acid with 2-(1-cyclohexenyl)cyclohexanone. Catal. Lett. 1998, 51, 121-127. [CrossRef]

60. Erdem, B.; Cebe, M. Kinetics of esterification of propionic acid with n-amyl alcohol in the presence of cation exchange resins. Korean J. Chem. Eng. 2006, 23, 896-901. [CrossRef]

61. Tesser, R.; Di Serio, M.; Casale, L.; Sannino, L.; Ledda, M.; Santacesaria, E. Acid exchange resins deactivation in the esterification of free fatty acids. Chem. Eng. J. 2010, 161, 212-222. [CrossRef]

62. Ferreira, P.; Fonseca, I.M.; Ramos, A.M.; Vital, J.; Castanheiro, J.E. Esterification of glycerol with acetic acid over dodecamolybdophosphoric acid encaged in USY zeolite. Catal. Commun. 2009, 10, 481-484. [CrossRef]

63. Farinha, J.; Caiado, M.; Castanheiro, J. Valorisation of glycerol into biofuel additives over heterogeneous catalysts. In Materials and Processes for Energy: Communicating Current Research and Technological Developments; Mendez-Vilas, A., Ed.; Formatex Research Center: Badajoz, Spain, 2013; pp. 422-429, ISBN 978-84-939843-7-3.

64. Silva, L.N.; Gonçalves, V.L.C.; Mota, C.J.A. Catalytic acetylation of glycerol with acetic anhydride. Catal. Commun. 2010, 11, 1036-1039. [CrossRef]

65. Kale, S.; Umbarkar, S.B.; Dongare, M.K.; Eckelt, R.; Armbruster, U.; Martin, A. Selective formation of triacetin by glycerol acetylation using acidic ion-exchange resins as catalyst and toluene as an entrainer. Appl. Catal. A Gen. 2015, 490, 10-16. [CrossRef]

66. Gadekar, S.V.; Naik, R.V.; Kaul, S.N. Entrainer for batch distillation of acetic acid-Water system. J. Sci. Ind. Res. 2009, 68, 871-875. 
67. Sad, M.E.; Duarte, H.A.; Vignatti, C.; Padró, C.L.; Apesteguía, C.R. Steam reforming of glycerol: Hydrogen production optimization. Int. J. Hydrogen Energy 2015, 40, 6097-6106. [CrossRef]

68. Ewan, B.C.R.; Allen, R.W.K. A figure of merit assessment of the routes to hydrogen. Int. J. Hydrogen Energy 2005, 30, 809-819. [CrossRef]

69. Sánchez, E.A.; D'Angelo, M.A.; Comelli, R.A. Hydrogen production from glycerol on $\mathrm{Ni} / \mathrm{Al}_{2} \mathrm{O}_{3}$ catalyst. Int. J. Hydrogen Energy 2010, 35, 5902-5907. [CrossRef]

70. Byrd, A.J.; Pant, K.K.; Gupta, R.B. Hydrogen production from glycerol by reforming in supercritical water over $\mathrm{Ru} / \mathrm{Al}_{2} \mathrm{O}_{3}$ catalyst. Fuel 2008, 87, 2956-2960. [CrossRef]

71. Tuza, P.; Manfro, R.L.; Ribeiro, N.F.P.; Souza, M.M.V.M. Production of renewable hydrogen by aqueous-phase reforming of glycerol over Ni-Cu catalysts derived from hydrotalcite precursors. Prog. Sustain. Energy Technol. Gener. Renew. Energy 2014, 1, 413-426. [CrossRef]

72. Hakim, L.; Yaakob, Z.; Ismail, M.; Daud, W.; Sari, R. Hydrogen production by steam reforming of glycerol over $\mathrm{Ni} / \mathrm{Ce} / \mathrm{Cu}$ hydroxyapatite-supported catalysts. Chem. Pap. 2013, 67, 703-712. [CrossRef]

73. Silva, J.M.; Soria, M.A.; Madeira, L.M. Challenges and strategies for optimization of glycerol steam reforming process. Renew. Sustain. Energy Rev. 2015, 42, 1187-1213. [CrossRef]

74. Adhikari, S.; Fernando, S.; Gwaltney, S.R.; Filip To, S.D.; Mark Bricka, R.; Steele, P.H.; Haryanto, A. A thermodynamic analysis of hydrogen production by steam reforming of glycerol. Int. J. Hydrogen Energy 2007, 32, 2875-2880. [CrossRef]

75. Valliyappan, T.; Ferdous, D.; Bakhshi, N.N.; Dalai, A.K. Production of hydrogen and syngas via steam gasification of glycerol in a fixed-bed reactor. Top. Catal. 2008, 49, 59-67. [CrossRef]

76. Jacobsen, H. "Heterogreeneous" chemistry: Catalysts for hydrogen production from biomass. Angew. Chem. Int. Ed. 2004, 43, 1912-1914. [CrossRef] [PubMed]

77. Davda, R.R.; Shabaker, J.W.; Huber, G.W.; Cortright, R.D.; Dumesic, J.A. A review of catalytic issues and process conditions for renewable hydrogen and alkanes by aqueous-phase reforming of oxygenated hydrocarbons over supported metal catalysts. Appl. Catal. B Environ. 2005, 56, 171-186. [CrossRef]

78. Wang, X.; Li, S.; Wang, H.; Liu, B.; Ma, X. Thermodynamic analysis of glycerin steam reforming. Energy Fuels 2008, 22, 4285-4291. [CrossRef]

79. He, L.; Parra, J.M.S.; Blekkan, E.A.; Chen, D. Towards efficient hydrogen production from glycerol by sorption enhanced steam reforming. Energy Environ. Sci. 2010, 3, 1046. [CrossRef]

80. Adhikari, S.; Fernando, S.; Haryanto, A. Production of hydrogen by steam reforming of glycerin over alumina-supported metal catalysts. Catal. Today 2007, 129, 355-364. [CrossRef]

81. Sutton, D.; Kelleher, B.; Ross, J.R.H. Review of literature on catalysts for biomass gasification. Fuel Process. Technol. 2001, 73, 155-173. [CrossRef]

82. Slinn, M.; Kendall, K.; Mallon, C.; Andrews, J. Steam reforming of biodiesel by-product to make renewable hydrogen. Bioresour. Technol. 2008, 99, 5851-5858. [CrossRef] [PubMed]

83. Stankiewicz, A. Reactive separations for process intensification: An industrial perspective. Chem. Eng. Process. 2003, 42, 137-144. [CrossRef]

84. Silva, J.M.; Soria, M.A.; Madeira, L.M. Thermodynamic analysis of Glycerol Steam Reforming for hydrogen production with in situ hydrogen and carbon dioxide separation. J. Power Sources 2015, 273, 423-430. [CrossRef]

85. Vasudeva, K.; Mitra, N.; Umasankar, P.; Dhingra, S.C. Steam reforming of ethanol for hydrogen production: Thermodynamic analysis. Int. J. Hydrogen Energy 1996, 21, 13-18. [CrossRef]

86. Lwin, Y.; Daud, W.R.W.; Mohamad, A.B.; Yaakob, Z. Hydrogen production from steam-methanol reforming: Thermodynamic analysis. Int. J. Hydrogen Energy 2000, 25, 47-53. [CrossRef]

87. Fishtik, I.; Alexander, A.; Datta, R.; Geana, D. Thermodynamic analysis of hydrogen production by steam reforming of ethanol via response reactions. Int. J. Hydrogen Energy 2000, 25, 31-45. [CrossRef]

88. Rossi, C.C.R.S.; Alonso, C.G.; Antunes, O.A.C.; Guirardello, R.; Cardozo-Filho, L. Thermodynamic analysis of steam reforming of ethanol and glycerine for hydrogen production. Int. J. Hydrogen Energy 2009, 34, 323-332. [CrossRef]

89. Dieuzeide, M.L.; Amadeo, N. Thermodynamic analysis of Glycerol steam reforming. Chem. Eng. Technol. 2010, 33, 89-96. [CrossRef]

90. Zhang, B.; Tang, X.; Li, Y.; Xu, Y.; Shen, W. Hydrogen production from steam reforming of ethanol and glycerol over ceria-supported metal catalysts. Int. J. Hydrogen Energy 2007, 32, 2367-2373. [CrossRef] 
91. Alcalá, R.; Mavrikakis, M.; Dumesic, J.A. DFT studies for cleavage of C-C and C-O bonds in surface species derived from ethanol on Pt(111). J. Catal. 2003, 218, 178-190. [CrossRef]

92. Chen, H.; Zhang, T.; Dou, B.; Dupont, V.; Williams, P.; Ghadiri, M.; Ding, Y. Thermodynamic analyses of adsorption-enhanced steam reforming of glycerol for hydrogen production. Int. J. Hydrogen Energy 2009, 34, 7208-7222. [CrossRef]

93. Dou, B.; Dupont, V.; Rickett, G.; Blakeman, N.; Williams, P.T.; Chen, H.; Ding, Y.; Ghadiri, M. Hydrogen production by sorption-enhanced steam reforming of glycerol. Bioresour. Technol. 2009, 100, 3540-3547. [CrossRef] [PubMed]

94. He, L.; Berntsen, H.; Ochoa-Fernández, E.; Walmsley, J.C.; Blekkan, E.A.; Chen, D. Co-Ni catalysts derived from hydrotalcite-like materials for hydrogen production by ethanol steam reforming. Top. Catal. 2009, 52, 206-217. [CrossRef]

95. Johnsen, K.; Ryu, H.J.; Grace, J.R.; Lim, C.J. Sorption-enhanced steam reforming of methane in a fluidized bed reactor with dolomite as CO2-acceptor. Chem. Eng. Sci. 2006, 61, 1195-1202. [CrossRef]

96. Li, Y.; Wang, Y.; Zhang, X.; Mi, Z. Thermodynamic analysis of autothermal steam and $\mathrm{CO}_{2}$ reforming of methane. Int. J. Hydrogen Energy 2008, 33, 2507-2514. [CrossRef]

97. Dou, B.; Rickett, G.L.; Dupont, V.; Williams, P.T.; Chen, H.; Ding, Y.; Ghadiri, M. Steam reforming of crude glycerol with in situ $\mathrm{CO}_{2}$ sorption. Bioresour. Technol. 2010, 101, 2436-2442. [CrossRef] [PubMed]

98. Zhang, T.; Zhou, Y.; Liu, D.; Petrus, L. Qualitative analysis of products formed during the acid catalyzed liquefaction of bagasse in ethylene glycol. Bioresour. Technol. 2007, 98, 1454-1459. [CrossRef] [PubMed]

99. Dou, B.; Wang, C.; Chen, H.; Song, Y.; Xie, B. Continuous sorption-enhanced steam reforming of glycerol to high-purity hydrogen production. Int. J. Hydrogen Energy 2013, 38, 11902-11909. [CrossRef]

100. Maroño, M.; Torreiro, Y.; Gutierrez, L. Influence of steam partial pressures in the $\mathrm{CO}_{2}$ capture capacity of K-doped hydrotalcite-based sorbents for their application to SEWGS processes. Int. J. Greenh. Gas Control 2013, 14, 183-192. [CrossRef]

101. Hanif, A.; Dasgupta, S.; Divekar, S.; Arya, A.; Garg, M.O.; Nanoti, A. A study on high temperature $\mathrm{CO}_{2}$ capture by improved hydrotalcite sorbents. Chem. Eng. J. 2014, 236, 91-99. [CrossRef]

102. Wang, Y.; Zhu, Y.; $\mathrm{Wu}, \mathrm{S}$. A new nano $\mathrm{CaO}$-based $\mathrm{CO}_{2}$ adsorbent prepared using an adsorption phase technique. Chem. Eng. J. 2013, 218, 39-45. [CrossRef]

103. Chowdhury, M.B.I.; Quddus, M.R.; DeLasa, H.I. $\mathrm{CO}_{2}$ capture with a novel solid fluidizable sorbent: Thermodynamics and Temperature Programmed Carbonation-Decarbonation. Chem. Eng. J. 2013, 232, 139-148. [CrossRef]

104. Wang, S.; An, C.; Zhang, Q.-H. Syntheses and structures of lithium zirconates for high-temperature $\mathrm{CO}_{2}$ absorption. J. Mater. Chem. A 2013, 1, 3540. [CrossRef]

105. Mizunuma, M.; Tsuda, M.; Maruo, Y.; Nakagaki, T. $\mathrm{CO}_{2}$ Capture System Using Lithium Silicate for Distributed Power Supply. Energy Procedia 2013, 37, 1194-1201. [CrossRef]

106. Martunus; Helwani, Z.; Wiheeb, A.D.; Kim, J.; Othman, M.R. Improved carbon dioxide capture using metal reinforced hydrotalcite under wet conditions. Int. J. Greenh. Gas Control 2012, 7, 127-136. [CrossRef]

107. Akgsornpeak, A.; Witoon, T.; Mungcharoen, T.; Limtrakul, J. Development of synthetic CaO sorbents via CTAB-assisted sol-gel method for $\mathrm{CO}_{2}$ capture at high temperature. Chem. Eng. J. 2014, 237, 189-198. [CrossRef]

108. Zhang, X.; Li, Z.; Peng, Y.; Su, W.; Sun, X.; Li, J. Investigation on a novel CaO- $\mathrm{Y}_{2} \mathrm{O}_{3}$ sorbent for efficient $\mathrm{CO}_{2}$ mitigation. Chem. Eng. J. 2014, 243, 297-304. [CrossRef]

109. Li, Y.; Wang, W.; Chen, B.; Cao, Y. Thermodynamic analysis of hydrogen production via glycerol steam reforming with $\mathrm{CO}_{2}$ adsorption. Int. J. Hydrogen Energy 2010, 35, 7768-7777. [CrossRef]

110. Gallucci, K.; Stendardo, S.; Foscolo, P.U. $\mathrm{CO}_{2}$ capture by means of dolomite in hydrogen production from syn gas. Int. J. Hydrogen Energy 2008, 33, 3049-3055. [CrossRef]

111. Alonso, M.; Rodríguez, N.; Grasa, G.; Abanades, J.C. Modelling of a fluidized bed carbonator reactor to capture $\mathrm{CO}_{2}$ from a combustion flue gas. Chem. Eng. Sci. 2009, 64, 883-891. [CrossRef]

112. Fermoso, J.; He, L.; Chen, D. Production of high purity hydrogen by sorption enhanced steam reforming of crude glycerol. Int. J. Hydrogen Energy 2012, 37, 14047-14054. [CrossRef]

113. Arstad, B.; Blom, R.; Bakken, E.; Dahl, I.; Jakobsen, J.P.; Røkke, P. Sorption-enhanced methane steam reforming in a circulating fluidized bed reactor system. Energy Procedia 2009, 1, 715-720. [CrossRef] 
114. Sutar, P.N.; Vaidya, P.D.; Rodrigues, A.E. Glycerol-reforming kinetics using a Pt/C catalyst. Chem. Eng. Technol. 2010, 33, 1645-1649. [CrossRef]

115. Cheng, C.K.; Foo, S.Y.; Adesina, A.A. $\mathrm{H}_{2}$-rich synthesis gas production over $\mathrm{Co} / \mathrm{Al}_{2} \mathrm{O}_{3}$ catalyst via glycerol steam reforming. Catal. Commun. 2010, 12, 292-298. [CrossRef]

116. Cheng, C.K.; Foo, S.Y.; Adesina, A.A. Steam reforming of glycerol over $\mathrm{Ni} / \mathrm{Al}_{2} \mathrm{O}_{3}$ catalyst. Catal. Today 2011, 178, 25-33. [CrossRef]

117. Cheng, C.K.; Foo, S.Y.; Adesina, A.A. Glycerol Steam Reforming over Bimetallic Co-Ni/ $\mathrm{Al}_{2} \mathrm{O}_{3}$. Ind. Eng. Chem. Res. 2010, 49, 10804-10817. [CrossRef]

118. Adhikari, S.; Fernando, S.D.; Haryanto, A. Kinetics and Reactor Modeling of Hydrogen Production from Glycerol via Steam Reforming Process over $\mathrm{Ni} / \mathrm{CeO}_{2}$ Catalysts. Chem. Eng. Technol. 2009, 32, 541-547. [CrossRef]

119. Dave, C.D.; Pant, K.K. Renewable hydrogen generation by steam reforming of glycerol over zirconia promoted ceria supported catalyst. Renew. Energy 2011, 36, 3195-3202. [CrossRef]

120. Calles, J.A.; Carrero, A.; Vizcaíno, A.J.; García-Moreno, L. Hydrogen production by glycerol steam reforming over SBA-15-supported nickel catalysts: Effect of alkaline earth promoters on activity and stability. Catal. Today 2014, 227, 198-206. [CrossRef]

121. Wang, C.; Dou, B.; Chen, H.; Song, Y.; Xu, Y.; Du, X.; Luo, T.; Tan, C. Hydrogen production from steam reforming of glycerol by Ni-Mg-Al based catalysts in a fixed-bed reactor. Chem. Eng. J. 2013, 220, 133-142. [CrossRef]

122. Liguras, D.K.; Kondarides, D.I.; Verykios, X.E. Production of hydrogen for fuel cells by steam reforming of ethanol over supported noble metal catalysts. Appl. Catal. B Environ. 2003, 43, 345-354. [CrossRef]

123. Adhikari, S.; Fernando, S.D.; To, S.D.F.; Bricka, R.M.; Steele, P.H.; Haryanto, A. Conversion of glycerol to hydrogen via a steam reforming process over nickel catalysts. Energy Fuels 2008, 22, 1220-1226. [CrossRef]

124. Pant, K.K.; Jain, R.; Jain, S. Renewable hydrogen production by steam reforming of glycerol over $\mathrm{Ni} / \mathrm{CeO}_{2}$ catalyst prepared by precipitation deposition method. Korean J. Chem. Eng. 2011, 28, 1859-1866. [CrossRef]

125. Leroi, P.; Madani, B.; Pham-Huu, C.; Ledoux, M.-J.; Savin-Poncet, S.; Bousquet, J.L. Ni/SiC: A stable and active catalyst for catalytic partial oxidation of methane. Catal. Today 2004, 91-92, 53-58. [CrossRef]

126. Rostrup-Nielsen, J.R. New aspects of syngas production and use. Catal. Today 2000,63, 159-164. [CrossRef]

127. Ledoux, M.J.; Pham-Huu, C. Silicon carbide a novel catalyst support for heterogeneous catalysis. Cattech 2001, 5, 226-246. [CrossRef]

128. Kim, S.M.; Woo, S.I. Sustainable production of syngas from biomass-derived glycerol by steam reforming over highly stable Ni/SiC. ChemSusChem 2012, 5, 1513-1522. [CrossRef]

129. Iriondo, A.; Barrio, V.L.; Cambra, J.F.; Arias, P.L.; Güemez, M.B.; Navarro, R.M.; Sánchez-Sánchez, M.C.; Fierro, J.L.G. Hydrogen production from glycerol over nickel catalysts supported on $\mathrm{Al}_{2} \mathrm{O}_{3}$ modified by $\mathrm{Mg}$, Zr, Ce or La. Top. Catal. 2008, 49, 46-58. [CrossRef]

130. Kitamura, S.; Su-Enaga, T.; Ikenaga, N.O.; Miyake, T.; Suzuki, T. Steam reforming of glycerin using Ni-based catalysts loaded on $\mathrm{CaO}-\mathrm{ZrO}_{2}$ solid solution. Catal. Lett. 2011, 141, 895-905. [CrossRef]

131. Buffoni, I.N.; Pompeo, F.; Santori, G.F.; Nichio, N.N. Nickel catalysts applied in steam reforming of glycerol for hydrogen production. Catal. Commun. 2009, 10, 1656-1660. [CrossRef]

132. Zhang, L.; Liu, J.; Li, W.; Guo, C.; Zhang, J. Ethanol steam reforming over Ni-Cu/ $\mathrm{Al}_{2} \mathrm{O}_{3}-\mathrm{MyOz}(\mathrm{M}=\mathrm{Si}$, $\mathrm{La}$, $\mathrm{Mg}$, and Zn) catalysts. J. Nat. Gas Chem. 2009, 18, 55-65. [CrossRef]

133. Djinović, P.; Batista, J.; Levec, J.; Pintar, A. Comparison of water-gas shift reaction activity and long-term stability of nanostructured $\mathrm{CuO}-\mathrm{CeO}_{2}$ catalysts prepared by hard template and co-precipitation methods. Appl. Catal. A Gen. 2009, 364, 156-165. [CrossRef]

134. Wang, X.; Rodriguez, J.A.; Hanson, J.C.; Gamarra, D.; Martínez-Arias, A.; Fernández-García, M. In situ studies of the active sites for the water gas shift reaction over $\mathrm{Cu}-\mathrm{CeO}_{2}$ catalysts: Complex interaction between metallic copper and oxygen vacancies of ceria. J. Phys. Chem. B 2006, 110, 428-434. [CrossRef] [PubMed]

135. Iriondo, A.; Barrio, V.L.; Cambra, J.F.; Arias, P.L.; Güemez, M.B.; Navarro, R.M.; Sanchez-Sanchez, M.C.; Fierro, J.L.G. Influence of $\mathrm{La}_{2} \mathrm{O}_{3}$ modified support and $\mathrm{Ni}$ and $\mathrm{Pt}$ active phases on glycerol steam reforming to produce hydrogen. Catal. Commun. 2009, 10, 1275-1278. [CrossRef]

136. Profeti, L.P.R.; Ticianelli, E.A.; Assaf, E.M. Production of hydrogen via steam reforming of biofuels on $\mathrm{Ni} / \mathrm{CeO}_{2}-\mathrm{Al}_{2} \mathrm{O}_{3}$ catalysts promoted by noble metals. Int. J. Hydrogen Energy 2009, 34, 5049-5060. [CrossRef] 
137. Zhou, C.H.; Zhao, H.; Tong, D.S.; Wu, L.M.; Yu, W.H. Recent advances in catalytic conversion of glycerol. Catal. Rev. Sci. Eng. 2013, 55, 369-453. [CrossRef]

138. Pompeo, F.; Santori, G.F.; Nichio, N.N. Hydrogen production by glycerol steam reforming with $\mathrm{Pt} / \mathrm{SiO}_{2}$ and $\mathrm{Ni} / \mathrm{SiO}_{2}$ catalysts. Catal. Today 2011, 172, 183-188. [CrossRef]

139. Soares, R.R.; Simonetti, D.A.; Dumesic, J.A. Glycerol as a source for fuels and chemicals by low-temperature catalytic processing. Angew. Chem. Int. Ed. 2006, 45, 3982-3985. [CrossRef] [PubMed]

140. Pompeo, F.; Santori, G.; Nichio, N.N. Hydrogen and/or syngas from steam reforming of glycerol. Study of platinum catalysts. Int. J. Hydrogen Energy 2010, 35, 8912-8920. [CrossRef]

141. Cui, Y.; Galvita, V.; Rihko-Struckmann, L.; Lorenz, H.; Sundmacher, K. Steam reforming of glycerol: The experimental activity of La1-xCe $\mathrm{N} \mathrm{NiO}_{3}$ catalyst in comparison to the thermodynamic reaction equilibrium. Appl. Catal. B Environ. 2009, 90, 29-37. [CrossRef]

142. Montini, T.; Singh, R.; Das, P.; Lorenzut, B.; Bertero, N.; Riello, P.; Benedetti, A.; Giambastiani, G.; Bianchini, C.; Zinoviev, S.; et al. Renewable $\mathrm{H}_{2}$ from Glycerol Steam Reforming: Effect of $\mathrm{La}_{2} \mathrm{O}_{3}$ and $\mathrm{CeO}_{2}$ Addition to $\mathrm{Pt} / \mathrm{Al}_{2} \mathrm{O}_{3}$ catalysts. ChemSusChem 2010, 3, 619-628. [CrossRef] [PubMed]

143. Greeley, J.; Mavrikakis, M. Alloy catalysts designed from first principles. Nat. Mater. 2004, 3, 810-815. [CrossRef] [PubMed]

144. Simonetti, D.A.; Kunkes, E.L.; Dumesic, J.A. Gas-phase conversion of glycerol to synthesis gas over carbon-supported platinum and platinum-rhenium catalysts. J. Catal. 2007, 247, 298-306. [CrossRef]

145. Hirai, T.; Ikenaga, N.O.; Miyake, T.; Suzuki, T. Production of hydrogen by steam reforming of glycerin on ruthenium catalyst. Energy Fuels 2005, 19, 1761-1762. [CrossRef]

146. Kim, J.; Lee, D. Glycerol steam reforming on supported Ru-based catalysts for hydrogen production for fuel cells. Int. J. Hydrogen Energy 2013, 38, 11853-11862. [CrossRef]

147. Iulianelli, A.; Liguori, S.; Wilcox, J.; Basile, A. Advances on methane steam reforming to produce hydrogen through membrane reactors technology: A review. Catal. Rev. Sci. Eng. 2016, 58, 1-35. [CrossRef]

148. Gallucci, F.; Fernandez, E.; Corengia, P.; van Sint Annaland, M. Recent advances on membranes and membrane reactors for hydrogen production. Chem. Eng. Sci. 2013, 92, 40-66. [CrossRef]

149. Adhikari, S.; Fernando, S. Hydrogen membrane separation techniques. Ind. Eng. Chem. Res. 2006, 45, 875-881. [CrossRef]

150. Basile, A.; Iulianelli, A.; Longo, T.; Liguori, S.; De Falco, M. Pd-based Selective Membrane State-of-the-Art. In Membrane Reactors for Hydrogen Production Processes; Springer: London, UK, 2011; pp. 21-55, ISBN 9788578110796.

151. Basile, A.; Iulianelli, A.; Tong, J. Single-stage hydrogen production and separation from fossil fuels using micro- and macromembrane reactors. In Compendium of Hydrogen Energy; Elsevier: Amsterdam, The Netherlands, 2015; pp. 445-468, ISBN 9781782423614.

152. Miguel, C.V.; Mendes, A.; Tosti, S.; Madeira, L.M. Effect of $\mathrm{CO}$ and $\mathrm{CO}_{2}$ on $\mathrm{H}_{2}$ permeation through finger-like Pd-Ag membranes. Int. J. Hydrogen Energy 2012, 37, 12680-12687. [CrossRef]

153. Mendes, D.; Chibante, V.; Zheng, J.-M.; Tosti, S.; Borgognoni, F.; Mendes, A.; Madeira, L.M. Enhancing the production of hydrogen via water-gas shift reaction using Pd-based membrane reactors. Int. J. Hydrogen Energy 2010, 35, 12596-12608. [CrossRef]

154. Santucci, A.; Borgognoni, F.; Vadrucci, M.; Tosti, S. Testing of dense Pd-Ag tubes: Effect of pressure and membrane thickness on the hydrogen permeability. J. Membr. Sci. 2013, 444, 378-383. [CrossRef]

155. Nayebossadri, S.; Speight, J.; Book, D. Effects of low Ag additions on the hydrogen permeability of Pd-Cu-Ag hydrogen separation membranes. J. Membr. Sci. 2014, 451, 216-225. [CrossRef]

156. Lewis, A.E.; Kershner, D.C.; Paglieri, S.N.; Slepicka, M.J.; Way, J.D. Pd-Pt/YSZ composite membranes for hydrogen separation from synthetic water-gas shift streams. J. Membr. Sci. 2013, 437, 257-264. [CrossRef]

157. Wei, L.; Yu, J.; Huang, Y. Silver coating on porous stainless steel substrate and preparation of $\mathrm{H}_{2}$-permeable palladium membranes. Int. J. Hydrogen Energy 2013, 38, 10833-10838. [CrossRef]

158. Wei, L.; Yu, J.; Hu, X.; Huang, Y. Fabrication of $\mathrm{H}_{2}$-permeable palladium membranes based on pencil-coated porous stainless steel substrate. Int. J. Hydrogen Energy 2012, 37, 13007-13012. [CrossRef]

159. Zhang, D.; Zhou, S.; Fan, Y.; Xu, N.; He, Y. Preparation of dense Pd composite membranes on porous Ti-Al alloy supports by electroless plating. J. Membr. Sci. 2012, 387-388, 24-29. [CrossRef] 
160. Braun, F.; Tarditi, A.M.; Miller, J.B.; Cornaglia, L.M. Pd-based binary and ternary alloy membranes: Morphological and perm-selective characterization in the presence of $\mathrm{H}_{2}$ S. J. Membr. Sci. 2014, 450, $299-307$. [CrossRef]

161. Basile, A.; Gallucci, F.; Iulianelli, A.; Tereschenko, G.F.; Ermilova, M.M.; Orekhova, N.V. Ti-Ni-Pd dense membranes-The effect of the gas mixtures on the hydrogen permeation. J. Membr. Sci. 2008, 310, 44-50. [CrossRef]

162. Peters, T.A.; Kaleta, T.; Stange, M.; Bredesen, R. Development of thin binary and ternary Pd-based alloy membranes for use in hydrogen production. J. Membr. Sci. 2011, 383, 124-134. [CrossRef] 